University of Wollongong

Research Online

Australian Institute for Innovative Materials -

Papers

Australian Institute for Innovative Materials

$1-1-2019$

Layer-structured niobium oxides and their analogues for advanced hybrid capacitors

Jiaqin Liao

Wei Ni

Caiyun Wang

University of Wollongong, caiyun@uow.edu.au

Jianmin Ma

Follow this and additional works at: https://ro.uow.edu.au/aiimpapers

Part of the Engineering Commons, and the Physical Sciences and Mathematics Commons

Research Online is the open access institutional repository for the University of Wollongong. For further information contact the UOW Library: research-pubs@uow.edu.au 


\title{
Layer-structured niobium oxides and their analogues for advanced hybrid capacitors
}

\author{
Abstract \\ (C) 2019 Elsevier B.V. Niobium-based oxides including niobium oxide (Nb205) and their analogues with \\ quasi-2D network of open and stable Wadsley-Roth shear crystal structure, have gained great interest for \\ advanced hybrid supercapacitors due to their outstanding rate capability derived from the intercalation \\ pseudocapacitive kinetics. To realize their full potential as battery-type anode electrodes for \\ supercapacitor, various strategies have been effectively implemented to overcome the drawbacks \\ especially the poor intrinsic electrical conductivity, including structure design, surface modification, \\ conductivity enhancement, and electrode engineering. Here, we provide a comprehensive overview of the \\ latest progress of $\mathrm{Nb}$-based oxides for high-rate hybrid supercapacitors in the aspects of structure- \\ performance relationship, performance-optimizing strategies, and energy storage mechanisms. We will \\ also present our insights into the challenges and perspectives for future development and industrial \\ applications.

\section{Disciplines} \\ Engineering | Physical Sciences and Mathematics

\section{Publication Details} \\ Liao, J., Ni, W., Wang, C. \& Ma, J. (2019). Layer-structured niobium oxides and their analogues for \\ advanced hybrid capacitors. Chemical Engineering Journal,
}




\title{
Layer-structured Niobium oxides and their Analogues for Advanced
}

\section{Hybrid Capacitors}

\author{
Jiaqin Liao, ${ }^{a}$ Wei Ni, ${ }^{b} *$ Caiyun Wang, ${ }^{c} *$ Jianmin $\mathrm{Ma}^{a, d}, *$ \\ ${ }^{a}$ School of Physics and Electronics, Hunan University, Changsha 410082, Hunan, China \\ ${ }^{b}$ College of Vanadium and Titanium, Panzhihua University, Panzhihua 617000, Sichuan, China \\ ${ }^{c}$ ARC Centre of Excellence for Electromaterials Science, Intelligent Polymer Research Institute, AIIM \\ Facility, University of Wollongong, North Wollongong, NSW 2500, Australia. \\ ${ }^{d}$ Key Laboratory of Materials Processing and Mold (Zhengzhou University), Ministry of Education, \\ Zhengzhou University, Zhengzhou 450002, Henan, China. \\ ${ }^{*}$ Corresponding authors.
}

E-mail addresses: niwei@iccas.ac.cn (W. Ni), caiyun@uow.edu.au (C. Wang), nanoelechem@hnu.edu.cn (J. Ma). 
Highlights:

1. The recent progress of Nb-based oxides for $\mathrm{Li}$ - and Na-ion hybrid capacitors is provided.

2. The aspects of structure, performance and energy storage mechanisms are summarized.

3. The challenges and perspectives for future development and applications are also presented.

TOC:

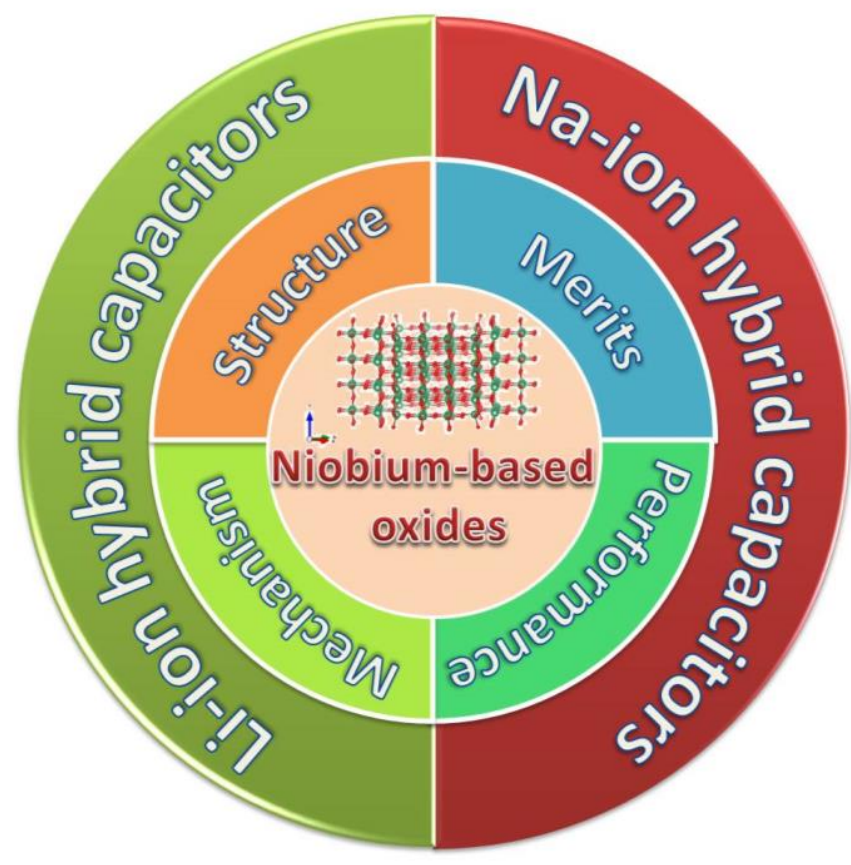

\begin{abstract}
Niobium-based oxides including niobium oxide $\left(\mathrm{Nb}_{2} \mathrm{O}_{5}\right)$ and their analogues with quasi-2D network of open and stable Wadsley-Roth shear crystal structure, have gained great interest for advanced hybrid supercapacitors due to their outstanding rate capability derived from the intercalation pseudocapacitive kinetics. To realize their full potential as battery-type anode electrodes for supercapacitor, various strategies have been effectively implemented to overcome the drawbacks especially the poor intrinsic electrical conductivity, including structure design, surface modification, conductivity enhancement, and electrode
\end{abstract}


engineering. Here, we provide a comprehensive overview of the latest progress of $\mathrm{Nb}$-based oxides for high-rate hybrid supercapacitors in the aspects of structure-performance relationship, performanceoptimizing strategies, and energy storage mechanisms. We will also present our insights into the challenges and perspectives for future development and industrial applications.

Keywords: Niobium oxides, 2D materials, nanocomposites, hybrid supercapacitors, structure-performance relationship 


\section{Introduction}

Hybrid supercapacitors (HSCs) that can combine the advantages of batteries and supercapacitors have been extensively investigated recently, in order to meet the increasing demands for high energy and power densities electrochemical energy-storage devices including electric vehicles (EVs) and hybrid electric vehicles (HEVs) [1-11]. HSCs, especially Na-HSCs, have shown great potential for mid- to large-scale energy storage applications due to their high energy/power densities, long cycle life, and low cost of sodium [12-17], and are considered as one of the most promising candidates for next-generation energy storage devices $[5,12]$. In the HSCs system, the capacitive (cathode) electrode can afford very high rate capability as the electrical charges are stored/released by ion adsorption/desorption; the alkali-ion battery electrode (anode) stores the energy via alkali-ion intercalation that suffers from relatively sluggish alkali-ion diffusion in the solid phase, and becomes the limiting factor of the rate performance [18]. To mitigate the rateimbalance issue in HSCs, much research effort has been devoted to the development of alkali-ion intercalation materials with ultrahigh rate capability and long cycle life [2, 3, 5, 19-24]. Materials with enhanced active sites (high capacity) and fast charge transport (high rate capability) can meet such requirement $[1,18]$. In particular, nanostructured materials with pseudocapacitive $\mathrm{Li} / \mathrm{Na}$-ion intercalation behavior have attracted attention, including layered transition-metal dichalcogenides (TMDs) and transition-metal oxides (TMOs) [16, 18, 25-36].

Among them, intercalation-type niobium-based oxides are considered as promising anode materials for Li/Na-ion capacitors owing to their high theoretical/practical capacities, fast ion diffusion, excellent chemical durability (long-term cyclability), and high safety [37-46]. Orthorhombic $\mathrm{Nb}_{2} \mathrm{O}_{5}\left(\mathrm{~T}-\mathrm{Nb}_{2} \mathrm{O}_{5}\right)$, with large interplanar lattice spacing $\left(3.9 \AA\right.$ ) $[47-49]$ and low potential plateau for anomalously fast $\mathrm{Li}^{+} / \mathrm{Na}^{+}$ diffusion and rapid pseudocapacitive response, have attracted a growing interest in recent years as anode material for high-performance Li/Na HSCs, which have demonstrated high energy and high power density even with practice-level volumetric specific capacity for thick electrodes [15, 18, 50-59]. Their analogues, e.g., layered titanium niobium oxide (TNO) [60] with unique Wadsley-Roth shear structure possess 
multiple electron reactions and niobium tungsten oxides with crystallographic shear or bronze-like structures, have the potential for achieving high pesudocapacitive capacitance and fast-charging/highpower applications [39, 44, 61-65]. However, the intrinsic low electrical conductivity and sluggish solidstate diffusion of alkali ions hinder their further practical application [15, 39, 61]. Different strategies have been applied to improve the electrochemical performance, mainly including the incorporation with conductive components or frameworks $[25,52,53,66,67]$, the design of nanoarchitectured electrode [40, $43,47,61,66]$, and enhancement of active sites [15, 39, 68].

Based on the intense research on niobium-based oxides with great advantages in promising HSCs. Here, we provide a timely and focused overview of the latest progress of Nb-based oxides for high-rate HSCs in the aspects of material/electrode design methods, structure-performance relationship, performanceoptimizing strategies, and energy storage mechanisms. We will also present our insights into the noteworthy challenges and perspectives for future development and industrial applications.

\section{Structure, merits and mechanism}

HSCs are usually composed of high-power electrochemical capacitor (EC) cathode and high-energy LIBs or NIBs anode, which perfectly combines the advantages of battery and capacitor energy storage mechanism. For Li/Na HSCs, charges are adsorbed/desorbed asymmetrically by the surface of capacitive cathode and via the reversible insertion/removal of $\mathrm{Li}^{+} / \mathrm{Na}^{+}$in the anode. As the potential ranges of two electrodes are different during the charge-discharge processes, it effectively expands the working potential window, thereby increasing the energy density of Li-HSCs. Advantages of HSCs mainly include: (1) higher cell capacity and energy density compared to EDLCs due to the high capacity from anode, (2) higher power density than LIBs/NIBs because of fast adsorption-desorption processes in cathode, (3) high reliability, (4) large operating temperatures, and (5) low self-discharge. Hybrid capacitors face challenges as well. The dynamic imbalance between the battery-type anode and capacitive-type cathode is a major disadvantage [3, $5]$. 
The key to manufacture high-performance HSCs is to select two matchable electrode materials. Due to its short charging-discharging time and high power capability, pseudocapacitor materials are candidates for high-performance HSCs [3, 5]. As one of the most promising and applicable insertion-type pseudocapacitive materials, layered $\mathrm{Nb}$-based oxides demonstrate obvious pseudocapacitive characteristics and high rate performance for Li/Na-ion storage compared with typical layered TMDs or TMOs. Herein, we will focus on the analysis of superior $\mathrm{T}-\mathrm{Nb}_{2} \mathrm{O}_{5}$ and its analogues [45].

\section{$2.1 \mathrm{~T}-\mathrm{Nb}_{2} \mathrm{O}_{5}$}

\subsubsection{Structure and merits}

There are five types of $\mathrm{Nb}_{2} \mathrm{O}_{5}$ crystals including pseudohexagonal $\mathrm{Nb}_{2} \mathrm{O}_{5}\left(\mathrm{TT}-\mathrm{Nb}_{2} \mathrm{O}_{5}\right)$, orthorhombic $\mathrm{Nb}_{2} \mathrm{O}_{5}\left(\mathrm{~T}-\mathrm{Nb}_{2} \mathrm{O}_{5}\right)$, tetragonal $\mathrm{Nb}_{2} \mathrm{O}_{5}\left(\mathrm{M}-\mathrm{Nb}_{2} \mathrm{O}_{5}\right)$, and monoclinic $\mathrm{Nb}_{2} \mathrm{O}_{5}\left(\mathrm{H}-\mathrm{Nb}_{2} \mathrm{O}_{5}\right)$; which are induced by the heat treatment environment $[69,70]$. It is well-recognized that the materials structure determines the derived performance. $\mathrm{Nb}_{2} \mathrm{O}_{5}$ in different crystal phase have demonstrated different electrochemical properties $[69,71,72]$. The mostly investigated $\mathrm{T}-\mathrm{Nb}_{2} \mathrm{O}_{5}$ shows the highest electrochemical performance due to the fast ion insertion-extraction mechanism and superior cycling stability, which will be the focus of the discussion in the following Section.

$\mathrm{T}-\mathrm{Nb}_{2} \mathrm{O}_{5}$ is composed of rhomboidal cells. Each $\mathrm{Nb}$ atom is surrounded by six or seven oxygen atoms, forming a twisted octahedron or pentagonal bipyramid. These polyhedra have edge sharing or angular sharing on the $a b$-plane and angular sharing on the $c$-axis [73]. According to the atomic arrangement in T$\mathrm{Nb}_{2} \mathrm{O}_{5}$, its crystal structure has two alternating atomic layers, the high density $4 \mathrm{~h}$ layer and the low density $4 \mathrm{~g}$ layer. The $4 \mathrm{~g}$ layer has more larger spaces for atomic capacity, providing the sites for storage and transmission of alkali ions [50]. Moreover, the adjacent $\mathrm{Nb}-\mathrm{O}$ bond structures in $\mathrm{T}-\mathrm{Nb}_{2} \mathrm{O}_{5}$ crystals endow alkali ions with two diffusion paths (Fig. 1, taking lithium ion as an example). The merits of its diffusion path have direct transmission channel, spacious space, small steric resistance and so on, which all promote the transmission of lithium ions [50]. Meanwhile, $\mathrm{T}_{-} \mathrm{Nb}_{2} \mathrm{O}_{5}$ has unique structural advantages: (001) empty 
octahedral positions between planes can provide stable and effective channels for lithium ion storage and transportation. When lithium ion is inserted into $\mathrm{T}-\mathrm{Nb}_{2} \mathrm{O}_{5}$, lithium ion is not constrained by its solid state diffusion, and only minimal phase transition and volume expansion occur [73]. Owing to the structurally and electronically exceptional merits of "room-and-pillar" layered structured of $\mathrm{T}-\mathrm{Nb}_{2} \mathrm{O}_{5}$, it possesses an intrinsic lower activation barrier for microscopic lithium diffusion (plus high ionic mobility and minimal strain), for example, and even the bulk structure facilitates high-rate lithium intercalation into large particles on par with the reported best nanostructured electrodes, which negates the usual requirement of short diffusion pathways or phase transition-suppressing nanostructures for rapid charge/discharge and benefits the practical application for advanced energy storage [71].

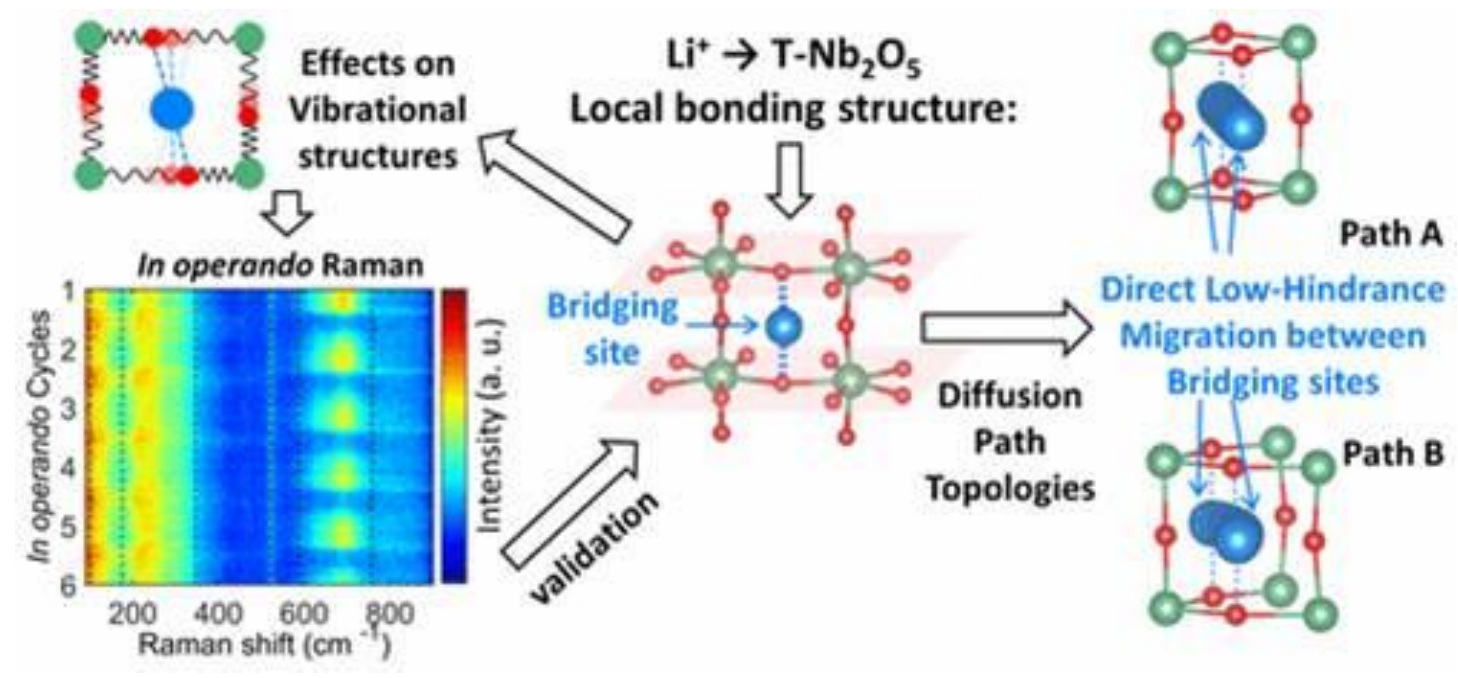

Fig. 1 A combination of experimental and computational investigations unveiling the mechanism of anomalously fast $\mathrm{Li}$-ion storage in $\mathrm{T}-\mathrm{Nb}_{2} \mathrm{O}_{5}$. (Reproduced with permission [50]. Copyright 2017, American Chemical Society.)

Despite $\mathrm{T}-\mathrm{Nb}_{2} \mathrm{O}_{5}$ affords many merits for alkali ions storage, it suffers from the relatively high voltage plateau $\left(\approx 1.5 \mathrm{~V}\right.$ vs. $\left.\mathrm{Li} / \mathrm{Li}^{+}\right)$leading to low energy density, and poor electrical conductivity $\left(\approx 3.4 \times 10^{-6}\right.$ $\mathrm{S} \mathrm{cm}^{-1}$ at $300 \mathrm{~K}$ ) resulting in slow dynamics that affects the high-rate capacity and cycling lifespan, all limiting its practical application as an anode of Li-HSCs [51, 53]. In order to improve the rate performance, $\mathrm{Nb}_{2} \mathrm{O}_{5}$ can be modified with carbon materials, structure optimization and heteroatom doping. The carbon 
modification (i.e. integration with graphene, carbon coating) is an easy and effective way to improve their electrical conductivity.

Na-HSCs and Li-HSCs share the similar electrochemical dynamics: the insertion of cations $\mathrm{Na}^{+}$or $\mathrm{Li}^{+}$ and anions from the electrolyte. However, the radius of sodium-ion (102 pm) is larger than that of lithium ion $(76 \mathrm{pm})$. The insertion of $\mathrm{Na}^{+}$into $\mathrm{Nb}_{2} \mathrm{O}_{5}$ causes larger volume expansion, resulting in slower diffusion rate and lower electrochemical performance. Nonetheless, the modification method of $\mathrm{Nb}_{2} \mathrm{O}_{5}$ for Li-HSCs can also be used to modify $\mathrm{Nb}_{2} \mathrm{O}_{5}$ based anode for Na-HSCs.

\subsubsection{Mechanism}

Various in situ or ex situ experimental characterization techniques have been used to study the lithiumion insertion mechanism in $\mathrm{Nb}_{2} \mathrm{O}_{5}$, such as in situ synchrotron radiation X-ray diffraction (XRD) and Xray absorption fine structure (XAFS) methods [74], X-ray absorption spectroscopy (XAS) and Fouriertransform of the extended XAFS measurements [51], XRD measurements combined with electrochemical analysis technique [54], ex situ high-resolution transmission electron microscopy (HR-TEM) [75], in operando Raman spectroscopy techniques [50], and nuclear magnetic resonance (NMR) techniques [71]. When Li-ions are embedded into $\mathrm{Nb}_{2} \mathrm{O}_{5}$, the structure changes of $\mathrm{Nb}_{2} \mathrm{O}_{5}$ are characterized as follows: (i) low volume change from the intercalation into the crystal lattices [74]; (ii) continuous valence variation of $\mathrm{Nb}\left(5^{+}\right.$to $\left.4^{+}\right)$with a two-stage intercalation reaction process [51]; (iii) fast Li-ion transport paths from the

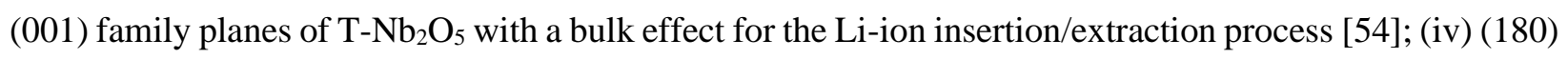
and (001) planes identified as the preferential tunnels for Li-ion transport [75].

As we know, cyclic voltammetry (CV) technique is commonly used to explore the electrochemical kinetics of Li-ion insertion/extraction process as follows [51]:

$$
\begin{aligned}
& i=a v^{b} \\
& \log (i)=\log (a)+b \log (v)
\end{aligned}
$$




$$
i(v)=k_{1} v+k_{2} v^{1 / 2}
$$

where $a$ and $b$ are adjustable parameters, $i$ is the current, and $v$ is the sweep rate. The value of $b$ can be calculated from $\log (i)$ versus $\log (v)$ plots. The $b$ value can reveal the nature of pseudocapacitive reaction: when it is close to 0.5 , the reaction is a diffusion-controlled process; when $b$ approaches 1 , this is a surfacecontrolled process. $k_{1} v$ and $k_{2} v^{1 / 2}$ represent surface-controlled capacitance and diffusion-controlled intercalation reactions, respectively. Through $k_{l} v$, the current value of the capacitive contribution under different potentials can be obtained to identify the contribution from capacitive and diffusion processes. This method has been widely used to determine whether the lithium ion insertion process in $\mathrm{T}-\mathrm{Nb}_{2} \mathrm{O}_{5}$ is a surface-controlled pseudocapacitive behavior or a diffusion control Faradaic behavior, as well as the corresponding contribution ratio.

Intercalation-type $\mathrm{T}-\mathrm{Nb}_{2} \mathrm{O}_{5}$ is a promising anode material for developing $\mathrm{Li} / \mathrm{Na} \mathrm{HSCs}$ due to its fast pseudocapacitive dynamics. Activated carbon (AC) is the widely cathode material because of its large specific surface area and excellent electrical double-layer capacitor (EDLCs) characteristics [76]. In order to achieve high energy and high power density, the rate performance and voltage window of each electrode (cathode, anode) at different current densities should be considered. The key to achieve high performance for $\mathrm{Nb}_{2} \mathrm{O}_{5}$ is to construct a structure facilitating ions transport for higher rate performance. Nanostructuring electrodes, enrichment of active sites, and compositing with conductive components are typical strategies to shorten ion/electron diffusion path and enhance rate performance. In this system, specific capacitance $(C)$, energy density $(E)$, and power density $(P)$ can be calculated using the following formulas [77]:

$$
\begin{aligned}
& C=I \Delta t / m \Delta V \\
& \Delta V=V_{\max }-V_{\text {min }} \\
& E=\int_{t_{1}}^{t_{2}} I V d t=0.5 C\left(V_{\text {max }}+V_{\min }\right)\left(V_{\text {max }}-V_{\min }\right) \\
& P=E / t
\end{aligned}
$$


where $I, \Delta t, m$, and $\Delta V$ represent the discharge current, discharge time, total mass of active substances at two electrodes, and voltage window of discharge curve, respectively. $\mathrm{The}^{+} / \mathrm{Na}^{+}$are quickly inserted into the $\mathrm{Nb}_{2} \mathrm{O}_{5}$ crystal and anions are adsorbed on the $\mathrm{AC}$ surface during charging, and vice visa for the discharging.

\subsection{Analogues}

Regarding to the analogues, layered titanium niobium oxides (TNO) mainly include $\mathrm{TiNb}_{2} \mathrm{O}_{7}$, $\mathrm{Ti}_{2} \mathrm{Nb}_{10} \mathrm{O}_{29}, \mathrm{TiNb}_{6} \mathrm{O}_{17}$, and $\mathrm{TiNb}_{24} \mathrm{O}_{62}$ [78-81]. Owing to the excellent lithium storage capability, $\mathrm{TiNb}_{2} \mathrm{O}_{7}$ has been extensively investigated for electrochemical energy storage, [45].

\subsubsection{Structure and merits}

$\mathrm{TiNb}_{2} \mathrm{O}_{7}$ owns a Wadsley-Roth shear crystal structure with high Li-ion diffusion coefficient, which consists of $m \times n \times \infty \mathrm{ReO}_{3}$-type blocks ( $m$ and $n$ mean the length and width of the blocks in numbers of octahedra, respectively) [45]). Both $m$ and $n$ are 3 for $\operatorname{TiNb}_{2} \mathrm{O}_{7}$, thus it has a layered monoclinic structure with a $C 2 / m$ space group [82]. $\mathrm{Ti}^{4+}$ and $\mathrm{Nb}^{5+}$ ions are in the octahedral sites that share corners and edges, disorderly. $\mathrm{TiNb}_{2} \mathrm{O}_{7}$ has an operating voltage of $\approx 1.6-1.7 \mathrm{~V} \mathrm{vs} \mathrm{Li}^{+} / \mathrm{Li}$ matching with the lowest unoccupied molecular orbital (LUMO) of organic liquid-carbonate electrolytes, which can avert the formation of SEI layer and lithium dendrite [65]. $\mathrm{TiNb}_{2} \mathrm{O}_{7}$ demonstrates good electrochemical performance when applied in LIBs, SIBs and HSCs. Its poor electrical conductivity and pulverization effect can be improved by structural engineering and carbon modification [83, 84].

\subsubsection{Mechanism}

$\mathrm{Li}^{+}$insert/extract into/from $\mathrm{TiNb}_{2} \mathrm{O}_{7}$ can be described as $\mathrm{TiNb}_{2} \mathrm{O}_{7}+x \mathrm{Li}^{+}+x \mathrm{e}^{-} \leftrightarrow \mathrm{Li}_{x} \mathrm{TiNb}_{2} \mathrm{O}_{7}, x$ is the mole fraction of the inserted $\mathrm{Li}^{+}$. When $x_{\max }$ reaches $5, \mathrm{TiNb}_{2} \mathrm{O}_{7}$ has a maximum theoretical capacity of 388 $\mathrm{mA} \mathrm{h} \mathrm{g}{ }^{-1}$ at $1.0-3.0 \mathrm{~V}\left(\mathrm{vs} \mathrm{Li}^{+} / \mathrm{Li}\right)$, resulting from three redox reactions $\left(\mathrm{Ti}^{4+} / \mathrm{Ti}^{3+}, \mathrm{Nb}^{5+} / \mathrm{Nb}^{4+}, \mathrm{and} \mathrm{Nb}^{4+} / \mathrm{Nb}^{3+}\right.$ [65]). The lithiation/delithiation mechanisms of $\mathrm{TiNb}_{2} \mathrm{O}_{7}$ crystal can be investigated by using the 
electrochemical characterization techniques and first-principles calculations [85]. The results indicate that the average lithium storage voltage is ca. $1.64 \mathrm{~V}$ and the inserted lithium ions are stored in the (001) plane of $\mathrm{TiNb}_{2} \mathrm{O}_{7}$ crystal with maintained layered structure. Catti et al. employed neutron diffraction technique and first-principles calculations to study the lithium insertion properties of $\mathrm{Li}_{x} \mathrm{TiNb}_{2} \mathrm{O}_{7}$. They found that the corner sharing was superior to edge sharing for transition metal atoms in the central row of the $3 \times 3$ block of octahedra, resulting in weaker chemical reduction of transition metal atoms [86].

\section{Li-ion hybrid capacitors}

Layered $\mathrm{Nb}_{2} \mathrm{O}_{5}$ polymorph is one of the most promising candidates for replacing conventional titanate electrodes to achieve high energy density in hybrid supercapacitor systems, due to it higher theoretical capacity ( $200 \mathrm{~mA} \mathrm{~h} \mathrm{~g}^{-1}$ or $\left.728 \mathrm{C} \mathrm{g}^{-1}\right)$ and outstanding high power performance $[1,55,61,87-89]$. The atomic arrangement of $\mathrm{T}-\mathrm{Nb}_{2} \mathrm{O}_{5}$, with open channels between quasi-2 $\mathrm{D} \mathrm{NbO}_{x}$ faces and multiple adsorption sites per unit-cell [41], affords the unique Li-ion diffusion path topologies, allowing the direct Li-ion transport between bridging sites with very low steric hindrance [50]. Even for bulk $\mathrm{Nb}_{2} \mathrm{O}_{5}$, it can be regarded as nanoporous material due to the interconnectedness of $\mathrm{NbO}_{x}$ sheets with sufficiently low energy barrier and facilitated local charge transfer [41]. However, the application of $\mathrm{Nb}_{2} \mathrm{O}_{5}$-based anodes in HSCs has been hindered by low electrical conductivity and difficulty in controlling the crystal structure [1]. Through surface modifications (e.g., the integration with carbon coating/supporting including CNTs [90-92], carbon nanofibers [93], carbon cloth [94], and grapheme [48, 63, 95-101], and the hybridization with highly conductive MXene [25, 66, 72, 77, 102-109]), heteroatom-doping and nanostructure engineering [54, 61, $66,88,97,108,110-116]$, the electron mobility in $\mathrm{Nb}_{2} \mathrm{O}_{5}$ can be substantially improved and thereof the performance [1, 97, 117-119].

For example, $\mathrm{Nb}$ foil was directly anodized to prepare $\mathrm{Nb}_{2} \mathrm{O}_{5}$ film with oriented nanochannels. Its lithium storage kinetics for hybrid supercapacitors were affected by not only the film morphology (e.g., pore size, thickness) but also the electron transport through the nanochannels that appears to be a major 
limiting factor particularly at high rate [111]. A conductive coating or phase transformation with higher crystallinity is needed for high-rate performance. Liu et al. designed and constructed $\mathrm{T}-\mathrm{Nb}_{2} \mathrm{O}_{5}$ quantum dots (QDs) embedded in MOF (ZIF-8) derived N-doped carbon (NQD-NC) with uniform rhombic dodecahedral morphology for HSCs [77]. The use of QDs structure with high dispersion provided large space to buffer the volume change of active materials. MOFs offered a new platform for fabricating novel nanoporous carbon materials-high-content $\mathrm{N}$-doped carbons with high surface area, large pore volume and excellent electronic characteristics for diverse electrochemical applications. Using the QDs-containing MOF derived NQD-NC hybrid as electrode material these Li-HSCs exhibited superior electrochemical performance including long-term cycling stability ( $\sim 82 \%$ capacity retention at $5 \mathrm{~A} \mathrm{~g}^{-1}$ over 3,000 cycles over a voltage window of $0.5-4.0 \mathrm{~V} ; \sim 85 \%$ retention over 4500 cycles at $0.5-3.0 \mathrm{~V}$ ) and a high energy density $\left(76.9 \mathrm{~W} \mathrm{~h} \mathrm{~kg}^{-1}\right)$ as well as high power density $\left(11.25 \mathrm{~kW} \mathrm{~kg}^{-1}\right)$ [77]. Song et al. fabricated a nanocomposite of microbe-derived porous carbon nanowebs (3D-CNWs) decorated with abundant ultrafine $\mathrm{T}-\mathrm{Nb}_{2} \mathrm{O}_{5}$ nanoparticles (Fig. 2a-d). The 3D-CNW/T- $-\mathrm{Nb}_{2} \mathrm{O}_{5}$ nanocomposite exhibited a remarkable stable long-term cycling performance over 70,000 cycles (Fig. 2e), a high reversible capacity (125 mA h g ${ }^{-1}$ ), and fast Li-ion storage kinetics. The assembled Li-HSCs coupled with activated carbon nanosheets (ACNs) cathode could deliver a high specific energy of $\sim 80 \mathrm{~W} \mathrm{~h} \mathrm{~kg}^{-1}$, a high specific power of $5.3 \mathrm{~kW} \mathrm{~kg}^{-1}$ as well as an extraordinary cycling performance with $\sim 80 \%$ capacitance retention over 35,000 cycles (Fig. 2f and $2 \mathrm{~g}$ ) [93]. The integration of ultrafine $\mathrm{T}-\mathrm{Nb}_{2} \mathrm{O}_{5}$ nanoparticles with microporous pyropolymer nanoplates (MPNPs, fabricated by controlled pyrolysis process of protein with the assistance of $\mathrm{KOH}$ ) could be endowed with even more excellent cycling stability with a $75 \%$ capacitance retention rate over 30,000 cycles due to the merits of functionalized carbonaceous materials with a number of redox-active heteroatoms and amorphous carbon microstructures (Fig. 3) [120]. 

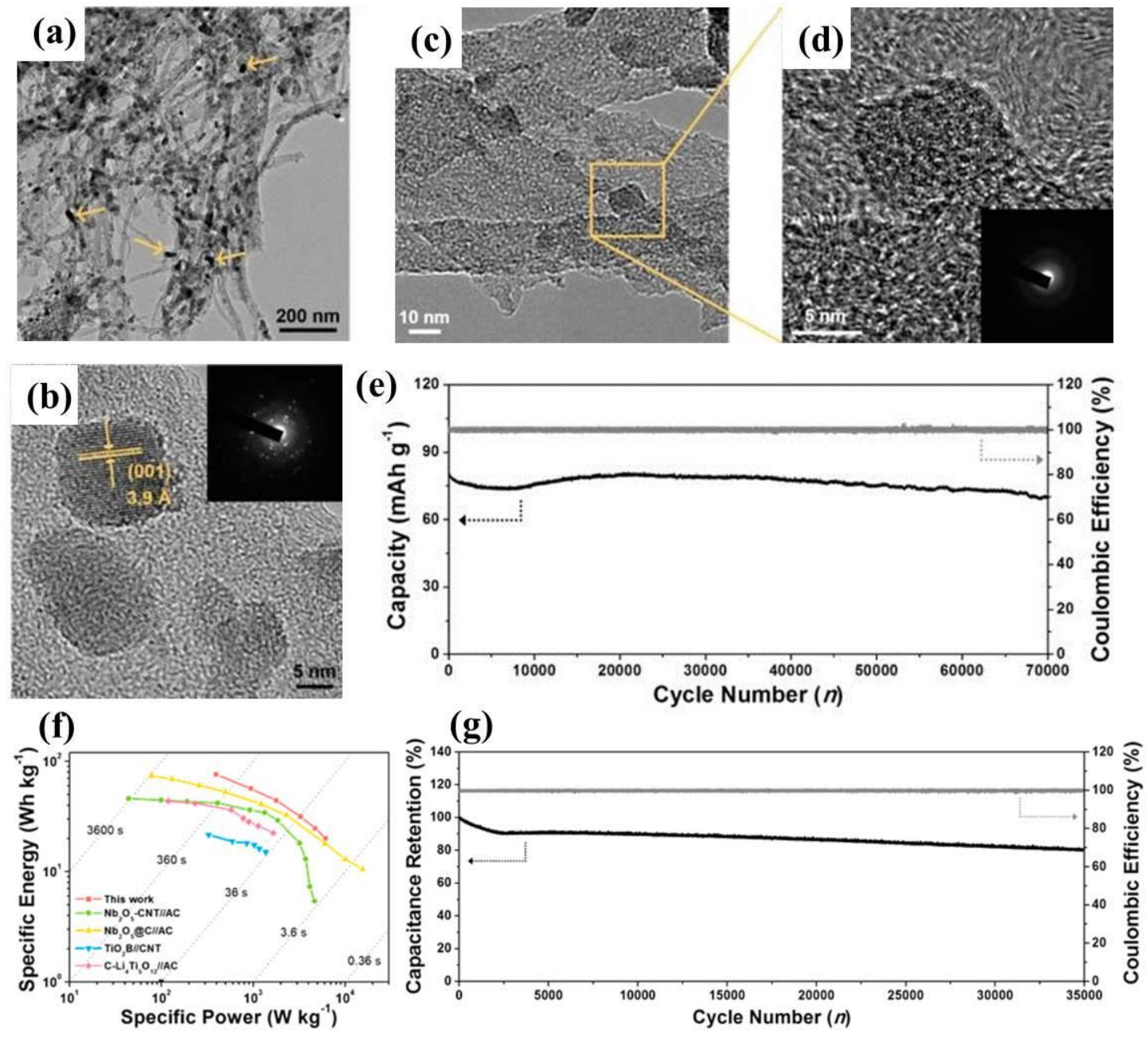

Fig. 2 Morphological characteristics of 3D-CNW/T- $-\mathrm{Nb}_{2} \mathrm{O}_{5}$ nanocomposites: (a) FETEM, (b) Highresolution FE-TEM image (inset, diffraction pattern of the selected area); (c) FE-TEM and (d) highresolution FE-TEM image after 70,000 cycles (inset, the selected area diffraction pattern). (e) Cycling performance of 3D-CNW/T- $\mathrm{Nb}_{2} \mathrm{O}_{5}$ nanocomposites tested over 70,000 cycles. (f) Ragone plots of several energy storage devices based on 3D-CNWs/T- $\mathrm{Nb}_{2} \mathrm{O}_{5} / / \mathrm{ACN}$ (squares), $\mathrm{Nb}_{2} \mathrm{O}_{5}$-CNT//AC (circles), $\mathrm{Nb}_{2} \mathrm{O}_{5} @ \mathrm{C} / / \mathrm{AC}$ (triangles), $\mathrm{TiO}_{2} \mathrm{~B} / / \mathrm{CNT}$ (inverse triangles), and $\mathrm{C}-\mathrm{Li}_{4} \mathrm{Ti}_{5} \mathrm{O}_{12} / / \mathrm{AC}$ (diamonds). (g) Cycling performance and Coulombic efficiency tested over 35,000 cycles. (Reproduced with permission [93]. Copyright 2016, American Chemical Society.) 


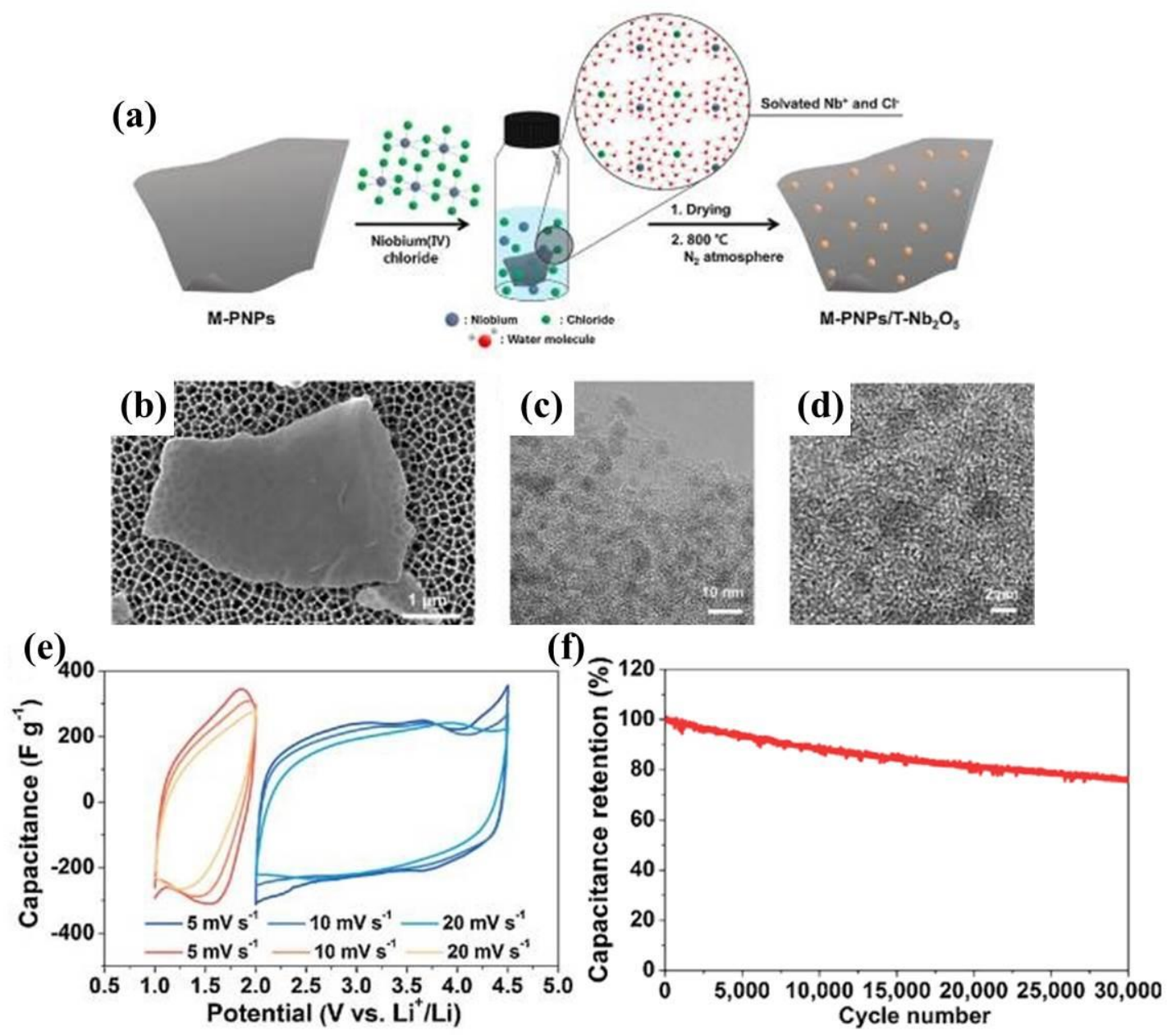

Fig. 3 (a) Schematic illustration of the preparation of M-PNP/T-Nb ${ }_{2} \mathrm{O}_{5}$ nanocomposite. (b) FE-SEM and (c and d) high-resolution FE-TEM images of M-PNP/T- $-\mathrm{Nb}_{2} \mathrm{O}_{5}$ nanocomposite. (e and f) Electrochemical performances of M-PNPs and M-PNP/T- $-\mathrm{Nb}_{2} \mathrm{O}_{5}$ nanocomposite, and full cell devices (LIHSs): (e) CVs at sweep rates from 5 to $20 \mathrm{mV} \mathrm{s}^{-1}$, (f) Cycling performance of the LIHSs (0-3.5 V vs. $\mathrm{Li}^{+} / \mathrm{Li}$ ) over 30,000 cycles. (Reproduced with permission [120]. Copyright 2017, The Korean Society of Industrial and Engineering Chemistry. Published by Elsevier B.V.)

$\mathrm{Lu}$ and coworkers synthesized a pseudohexagonal $\mathrm{Nb}_{2} \mathrm{O}_{5} / \mathrm{CNTs}$ composite (hydrothermal at $200{ }^{\circ} \mathrm{C}$ and annealing at $300{ }^{\circ} \mathrm{C}$ ) but with low specific capacity, not sufficient for high-performance HSC system due to the strong capacity-dependency on the crystal structure [49]. Compared with pseudohexagonal and amorphous phases, the orthorhombic phase has shown the highest specific capacity [75, 117]. Lim et al. synthesized $\mathrm{Nb}_{2} \mathrm{O}_{5} @ \mathrm{C}$ core-shell nanocrystals $\left(\mathrm{Nb}_{2} \mathrm{O}_{5} @ \mathrm{C} \mathrm{NCs}\right)$ with controlled crystalline structure for high-power anodes in HSCs. Via easily controlling the $\mathrm{pH}$ condition in the water-in-oil microemulsion 
system, the $\mathrm{T}-\mathrm{Nb}_{2} \mathrm{O}_{5} @ \mathrm{C}$ NCs structures can be prepared in a facile and straightforward route (Fig.4 a-b) [117]. They also designed and prepared a mesoporous orthorhombic $\mathrm{Nb}_{2} \mathrm{O}_{5} /$ carbon $\left(\mathrm{m}-\mathrm{Nb}_{2} \mathrm{O}_{5}-\mathrm{C}\right)$ nanocomposite by a simple one-pot method using a block copolymer assisted self-assembly (Fig. 4c and 4d) [1]. The m-Nb${ }_{2} \mathrm{O}_{5}-\mathrm{C}$ anode provided high specific capacity with outstanding rate performance and cyclability, which mainly originated from its enhanced pseudocapacitive behavior (linear relationship between $i$ and $v$, i.e., Fig. 4e) through introduction of a carbon-coated mesostructure within a voltage range of 3.0-1.1 V (vs. $\left.\mathrm{Li} / \mathrm{Li}^{+}\right)$. The HSCs using the $\mathrm{m}-\mathrm{Nb}_{2} \mathrm{O}_{5}-\mathrm{C}$ anode and commercial activated carbon (MSP20) cathode in organic electrolyte delivered a high power density ( $18510 \mathrm{~W} \mathrm{~kg}^{-1}$ at $\left.15 \mathrm{~W} \mathrm{~h} \mathrm{~kg}^{-1}\right)$, bridging the performance gap between conventional batteries and supercapacitors (Fig. 4f) [1].
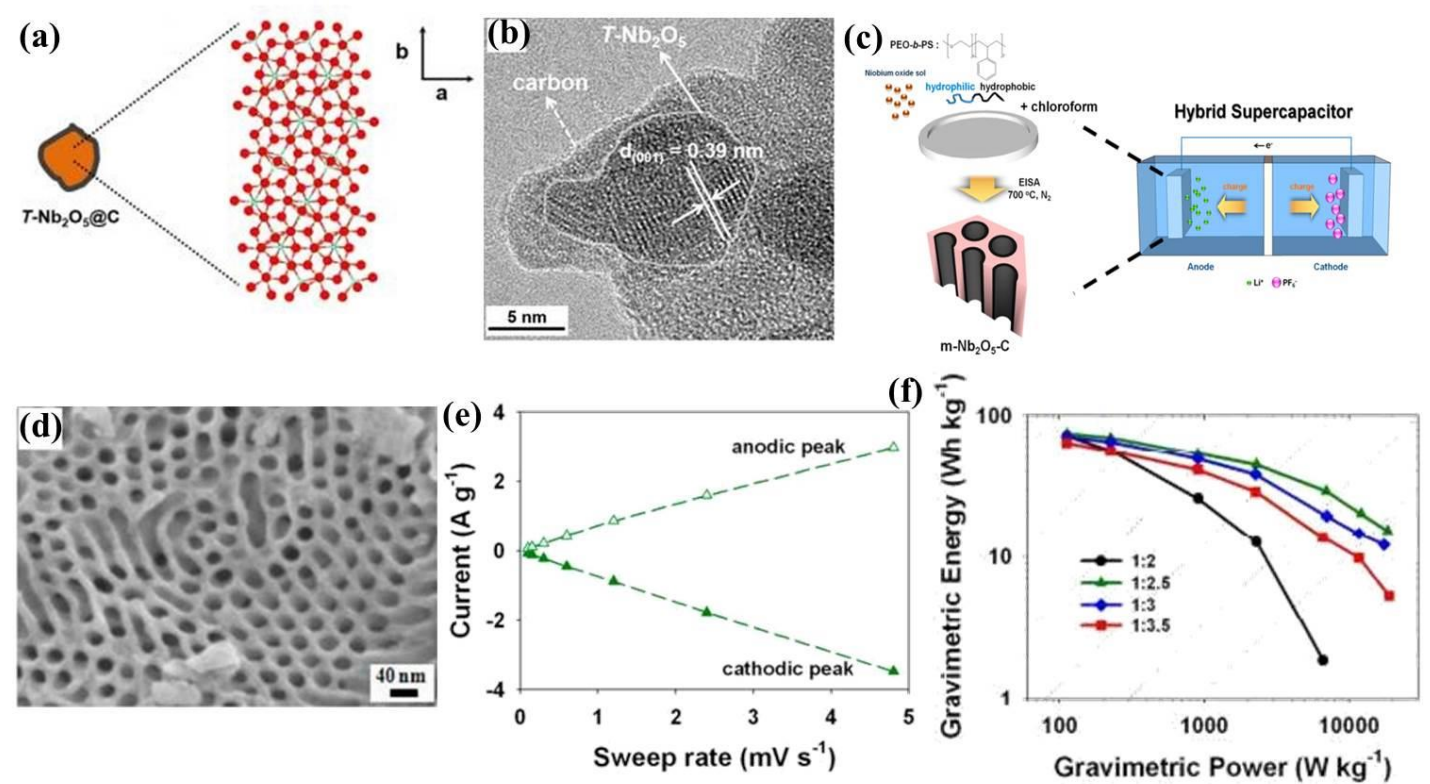

Fig. 4 Structural schemes of (a) $\mathrm{T}-\mathrm{Nb}_{2} \mathrm{O}_{5}$ (green, $\mathrm{Nb}$ atom; red, $\mathrm{O}$ atom), and (b) the TEM image of T$\mathrm{Nb}_{2} \mathrm{O}_{5} @ \mathrm{C} \mathrm{NCs}$. (c) Schematic diagram of one-pot synthesis of m- $\mathrm{Nb}_{2} \mathrm{O}_{5}-\mathrm{C}$ and a hybrid supercapacitor system comprising m-Nb $\mathrm{O}_{5}$-C anode and MSP-20 cathode. (d) HR-TEM image of m- $\mathrm{Nb}_{2} \mathrm{O}_{5}-\mathrm{C}$. (e) Specific peak current of $\mathrm{m}-\mathrm{Nb}_{2} \mathrm{O}_{5}-\mathrm{C}$ electrode for sweep rates ranging from 0.1 to $4.8 \mathrm{mV} \mathrm{s}^{-1}$. (f) Ragone plots of hybrid supercapacitors based on $\mathrm{m}-\mathrm{Nb}_{2} \mathrm{O}_{5}-\mathrm{C}$ and MSP-20 with different mass ratio of active materials on anode and cathode in the voltage range of 0.5-3.5 V. (a-b) Reproduced with permission [117]. Copyright 
2015, American Chemical Society. (c-f) Reproduced with permission [1]. Copyright 2014, American Chemical Society.

In addition to the $\mathrm{Nb}_{2} \mathrm{O}_{5}$ nanowires synthesized by hydrothermal or microwave-assisted solution synthesis approach [48, 108], Wang and Shen fabricated $\mathrm{TiNb}_{2} \mathrm{O}_{7} @ \mathrm{C}$ thin wires via an electrospinning method to achieve higher capacity (theoretical value $387.6 \mathrm{~mA} \mathrm{~h} \mathrm{~g}^{-1}$ ) [40] from the involved multiple redox couples [83], owing to the fact that $\mathrm{TiNb}_{2} \mathrm{O}_{7}$ is a promising insertion host for hybrid capacitors or high-rate batteries due to its high theoretical capacity (about 2 times higher than its conventional counterpart $\mathrm{Li}_{4} \mathrm{Ti}_{5} \mathrm{O}_{12}$ ), excellent reversibility, long cycle life and high safety [61]. The 1D hybrid material, as a Li-ion intercalation pseudocapacitance electrode, demonstrated a high capacity of $280 \mathrm{~mA} \mathrm{~g}^{-1}$ at $0.2 \mathrm{~A} \mathrm{~g}^{-1}$ over the voltage range of 1.0-3.0 $\mathrm{V} v$ s. $\mathrm{Li}^{+} / \mathrm{Li}$, and a superior specific capacitance of $759 \mathrm{~F} \mathrm{~g}^{-1}$ at $0.1 \mathrm{~A} \mathrm{~g}^{-1}$ between 1.0 and $2.0 \mathrm{~V}$. The carbon coating and interstitial spaces improved the electronic conductivity and the subsequent rate capabilities. When coupled with carbon fibers cathode, the hybrid supercapacitor could deliver an ultrahigh energy density of $110.4 \mathrm{~W} \mathrm{~h} \mathrm{~kg}^{-1}$ at a power density of $99.6 \mathrm{~W} \mathrm{~kg}^{-1}$, and an excellent power density of $5464 \mathrm{~W} \mathrm{~kg}^{-1}$ at an energy density of $20 \mathrm{~W} \mathrm{~h} \mathrm{~kg}^{-1}$, indicating the potential application in EVs and HEVs [83]. A similar work had been demonstrated by Aravindan et al. by using electrospun $\mathrm{TiNb}_{2} \mathrm{O}_{7}$ nanowires (with an evaluated $3.45 \mathrm{~mol}$ reversible intercalation of lithium in half-cell configuration) as anode and coconut shell-derived activated carbon as cathode for high-performance HSCs [84].

Hierarchical structures benefit the electron transfer and ion diffusion for rapid electrochemical kinetics as well as maintain structural integrity of the electrode during high-rate and repeated charging-discharging. Those mesoporous nanospheres [97], hollow spheres [107], urchin-/flower-like microspheres [118, 121, 122], porous nanotubes [61], yolk-core microspheres [123] with hierarchical structures have shown extraordinary pseduocapacitive properties for Li-HSCs. The construction of core-shell nanostructure with highly conductive shell is an effective strategy to achieve better electrochemical performance. The porous carbon shell with hollow structure not only provide high surface area and rapid ion diffusion channels for improved rate capability but also alleviate the aggregation of active core for enhanced cycling stability 
[124]. Take $\mathrm{T}-\mathrm{Nb}_{2} \mathrm{O}_{5}$ nanoparticles confined within the mesoporous hollow carbon nanospheres $\left(\mathrm{Nb}_{2} \mathrm{O}_{5} @ \mathrm{MC}\right)$ as an example (Fig. 5), this hybrid could deliver a high initial reversible specific capacity of $410 \mathrm{C} \mathrm{g}^{-1}$ at $1.0 \mathrm{~A} \mathrm{~g}^{-1}$ and an outstanding rate capability of $173 \mathrm{C} \mathrm{g}^{-1}$ at $50 \mathrm{~A} \mathrm{~g}^{-1}$. When paired up with mesoporous carbon hollow nanospheres cathode, the assembled HSCs achieved superior high energy and power densities simultaneously, especially regarding to the ultrahigh power density, which is attractive for a wide range of power delivery applications [124]. They also prepared yolk-shell $\mathrm{Nb}_{2} \mathrm{O}_{5}\left(\mathrm{YS}-\mathrm{Nb}_{2} \mathrm{O}_{5}\right)$ microspheres with outstanding intercalation pseudocapacitance via a scalable spray drying method. YS$\mathrm{Nb}_{2} \mathrm{O}_{5}-600 / / \mathrm{AC}$ Li-HSCs delivered an ultrahigh energy density $\left(173 \mathrm{~W} \mathrm{~h} \mathrm{~kg}^{-1}\right)$, high power delivery $(10.8$ $\mathrm{kW} \mathrm{kg}^{-1}$ ), and outstanding cyclability ( $98 \%$ capacity retention after 1000 cycles). This work provides important insight into the proper design of pseudocapacitance anode materials for high-performance LiHSCs [123].

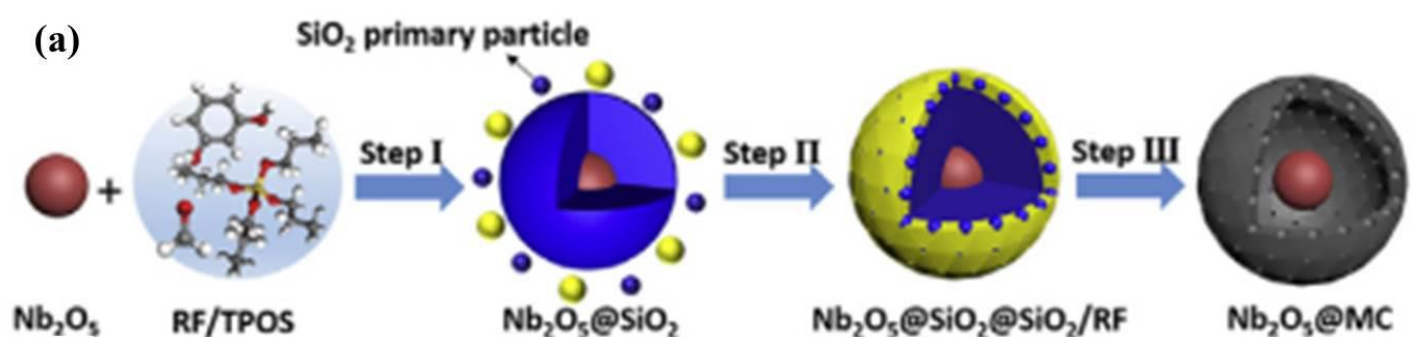

(b)

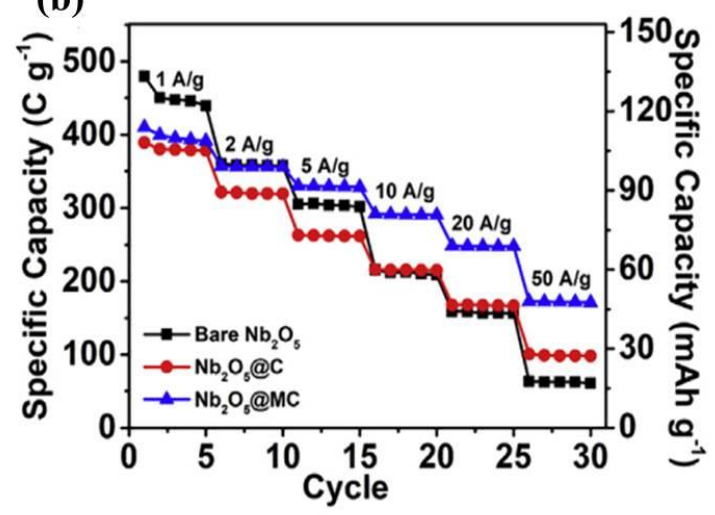

(c)

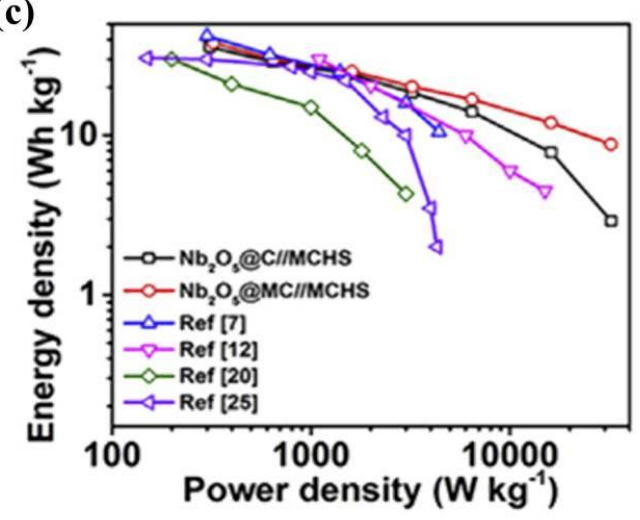

Fig. 5 (a) Schematic illustrations of the synthesis of $\mathrm{Nb}_{2} \mathrm{O}_{5} @ \mathrm{MC}$ hollow core-shell nanostructures. (b) Rate capability of $\mathrm{Nb}_{2} \mathrm{O}_{5} @ \mathrm{MC}$. (c) Ragone plots of $\mathrm{Nb}_{2} \mathrm{O}_{5} @ \mathrm{C} / / \mathrm{MCHS}$ and $\mathrm{Nb}_{2} \mathrm{O}_{5} @ \mathrm{MC} / / \mathrm{MCHS}$ hybrid supercapacitors. (Reproduced with permission [124]. Copyright 2018 Elsevier B.V.) 
Homogeneously distributing $\mathrm{T}-\mathrm{Nb}_{2} \mathrm{O}_{5}$ nanoparticles in a highly conductive matrix is a promising approach to maximize energy and power densities [25, 102]. Gogotsi and coworkers designed a hierarchical $\mathrm{Nb}_{2} \mathrm{O}_{5} / \mathrm{C} / \mathrm{MX}$ ene hybrid material with $\mathrm{T}-\mathrm{Nb}_{2} \mathrm{O}_{5}$ NPs uniformly anchored on the surface of conductive MXene sheets with disordered carbon via the one-step controllable $\mathrm{CO}_{2}$ (partial) oxidation of 2D niobium carbide $\left(\mathrm{Nb}_{2} \mathrm{CT}_{x}\right)$ (Fig. 6a-c) [25]. The MXene composition and oxidation conditions affected the crystallite size of $\mathrm{T}-\mathrm{Nb}_{2} \mathrm{O}_{5}$, the structure, composition, and charge storage properties of the formed hybrid material. A $50-\mu \mathrm{m}$ thick electrode of this hybrid material with a high mass loading of $2.4 \mathrm{mg} \mathrm{cm}^{-2}$ that was comparable to commercial devices and much higher than most of the reported $\mathrm{Nb}_{2} \mathrm{O}_{5}$-based materials delivered an optimum capacitance of $330 \mathrm{C} \mathrm{g}^{-1}$ or $660 \mathrm{mF} \mathrm{cm}^{-2}$ within a charge/discharge time of $4 \mathrm{~min}$, a $430 \mathrm{mF} \mathrm{cm}^{-2}$ at a charge/discharge time of $1 \mathrm{~min}$, and good cycling performance in an organic lithium electrolyte. The charge storage kinetics were dominated by a surface-controlled process. The enhanced electrochemical performance could be attributed to the synergistic effects from the intrinsic fast pseudocapacitive response and excellent energy storage capability of $\mathrm{T}-\mathrm{Nb}_{2} \mathrm{O}_{5}$ along with the fast charge transfer pathway provided by the highly conductive 2D MXene sheets and the carbide-derived disordered carbon (Fig. 6d-f) [25]. Direct pyrolysis of Nb-based coordination polymers or metal organic frameworks (MOFs) is also a facile and effective approach for fabricating $\mathrm{Nb}_{2} \mathrm{O}_{5} / \mathrm{C}$ nanocomposites with well-defined $T-\mathrm{Nb}_{2} \mathrm{O}_{5}$ nanoparticles embedded in uniform carbon coating $[101,104]$. Such $\mathrm{T}-\mathrm{Nb}_{2} \mathrm{O}_{5} / \mathrm{C}$ exhibited a higher capacity and much better rate capability compared to commercial $\mathrm{Nb}_{2} \mathrm{O}_{5}$. The built Li-HSCs using $\mathrm{Nb}_{2} \mathrm{O}_{5}$-based anode and $\mathrm{N}$ doped activated carbon cathode delivered a superior energy density $\left(92 \mathrm{~W} \mathrm{~h} \mathrm{~kg}^{-1}\right)$ and higher power density $\left(17.5 \mathrm{~kW} \mathrm{~kg}^{-1}\right)$ with a wide voltage window of $0-3.5 \mathrm{~V}$, as well as outstanding long-term cycling performance over 10,000 cycles at $2 \mathrm{~A} \mathrm{~g} \mathrm{~g}^{-1}$ with a capacitance retention rate of $86 \%$ [104]. 

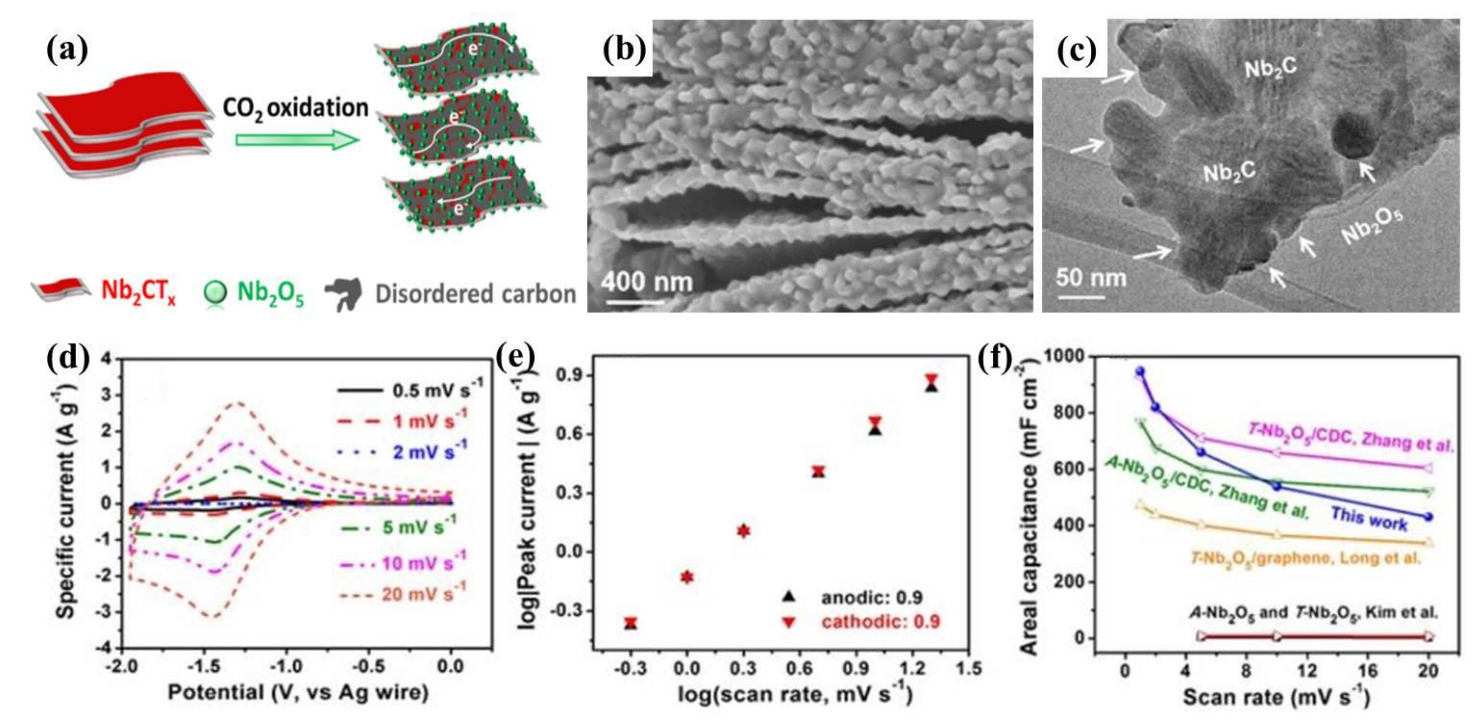

Fig. 6 (a) Schematic illustration of the preparation of hierarchical $\mathrm{Nb}_{2} \mathrm{O}_{5} /$ carbon/ $/ \mathrm{Nb}_{2} \mathrm{CT}_{x}$ material and the corresponding (b) SEM and (c) TEM images. Electrochemical properties: (d) CV curves at different scan rates, the slightly change of peak potentials suggesting the fast charge/discharge capability; (e) a plot for $b$ value determination, the calculated values of 0.9 indicating the surface-controlled process; and (f) areal capacitance of the as-prepared hybrid material compared to other $\mathrm{Nb}_{2} \mathrm{O}_{5}$-based electrode systems. (Reproduced with permission [25]. Copyright 2016, American Chemical Society.)

Graphene, a 2D atom-thick material with extraordinary physicochemical properties, has been used as an ideal highly conductive matrix for the hybridization of high-capacity components $[53,63,95-98,101,118$, 125-131]. For example, Jiao et al. fabricated a $\mathrm{T}_{-}-\mathrm{Nb}_{2} \mathrm{O}_{5}$ nanowire/reduced graphene oxide (rGO) nanohybrid via a hydrothermal approach followed by a high-temperature phase transformation [95]. It displayed enhanced reversible capacity and cycling stability compared to that of pristine $\mathrm{T}-\mathrm{Nb}_{2} \mathrm{O}_{5} \mathrm{NWs}$ electrode owing to the strong bonds and synergistic effects between the $2 \mathrm{D}$ graphene and $1 \mathrm{D} \mathrm{T}-\mathrm{Nb}_{2} \mathrm{O}_{5} \mathrm{NWs}$. Non-aqueous asymmetric supercapacitors (ASCs) were fabricated with a polymer ionogel separator and formulated ionic liquid electrolyte when coupled with activated carbon (AC) cathode. The $4 \mathrm{~V}$ quasi-solid state ASC could operate at high temperature $\left(60^{\circ} \mathrm{C}\right)$ with enhanced safety as well as superior energy and power densities $\left(70 \mathrm{~W} \mathrm{~h} \mathrm{~kg}^{-1}\right.$ at $\left.1 \mathrm{~kW} \mathrm{~kg}^{-1}\right)$. Thus, it may serve as a strong competitor for the next generation 
of hybrid supercapacitors in HEVs [95]. After the incorporation with graphene (e.g., rGO) the monoclinic $\mathrm{Nb}_{2} \mathrm{O}_{5}\left(\mathrm{H}-\mathrm{Nb}_{2} \mathrm{O}_{5}\right)$ could be also improved to compete with the intensively investigated $\mathrm{T}-\mathrm{Nb}_{2} \mathrm{O}_{5}$ polymorph in high-performance electrochemical energy storage due to the merits of nanocomposites (large specific surface area, porous structure and intimate interface) and synergistic effects on the enhancement of their electrochemical performance [132]. Other nanocomposites, including $\mathrm{H}-\mathrm{Nb}_{2} \mathrm{O}_{5} / 2 \mathrm{D} g-\mathrm{C}_{3} \mathrm{~N}_{4}$, flower-like $\mathrm{MnNb}_{2} \mathrm{O}_{6} / \mathrm{rGO}$ and holey graphene-wrapped porous $\mathrm{TiNb}_{24} \mathrm{O}_{62}$ micropsheres are also synthesized to demonstrate the ease of implementation and universality of such strategy [62, 63, 132]. As an example, Zhang et al. synthesized flower-like $\mathrm{MnNb}_{2} \mathrm{O}_{6}$ anchored on $\mathrm{rGO}$ sheet composites to enhance the electronic conductivity of columbite Nb-based metal oxides. The uniform distribution of $\mathrm{MnNb}_{2} \mathrm{O}_{6}$ particles on rGO sheets and their synergistic effects between $\mathrm{rGO}$ and $\mathrm{MnNb}_{2} \mathrm{O}_{6}$ endowed the composite with superior lithium storage capacity (460 $\mathrm{mA} \mathrm{h} \mathrm{g}^{-1}$ at $50 \mathrm{~mA} \mathrm{~g}^{-1}$ ) and good cycling stability. The assembled $\mathrm{MnNb}_{2} \mathrm{O}_{6} @ \mathrm{rGO} / / \mathrm{AC}$ Li-HSCs demonstrated a maximum energy density of $118 \mathrm{~W} \mathrm{~h} \mathrm{~kg}^{-1}$ (at $100 \mathrm{~W} \mathrm{~kg}^{-1}$ ) and power density of $8 \mathrm{~kW} \mathrm{~kg}^{-1}$ (at $68.5 \mathrm{~W} \mathrm{~h} \mathrm{~kg}^{-1}$ ) as well as a high capacity retention rate of $88 \%$ after 10,000 cycles, surpassing that of typical bimetallic oxide materials reported so far [62].

Free-standing or flexible electrodes with high gravimetrical/volumetric capacitance are promising electrode for applications in the emerging flexible electronics $[39,94,115,133]$. Long and coworkers prepared free-standing $\mathrm{T}-\mathrm{Nb}_{2} \mathrm{O}_{5} /$ graphene composite papers with ultrathin $\mathrm{Nb}_{2} \mathrm{O}_{5}$ nanoparticles homogenously decorated on graphene as Li-intercalating pseudocapacitive electrodes for HSCs (Fig. 7a-e), via a facile polyol-mediated solvothermal reaction followed by filtration and heat-treatment. T$\mathrm{Nb}_{2} \mathrm{O}_{5}$ /graphene composite papers possessed a nanoporous layer-stacked structure with good ionic/electronic conduction pathways, and demonstrated a superior pseudocapacitor performance, e.g., an ultrahigh gravimetric/volumetric capacitance $\left(620.5 \mathrm{~F} \mathrm{~g}^{-1}\right.$ and $961.8 \mathrm{~F} \mathrm{~cm}^{-3}$ at $\left.1 \mathrm{mV} \mathrm{s}^{-1}\right)$ and excellent rate capability (Fig. 7f and 7g). The assembled asymmetric supercapacitor configuration based on $\mathrm{T}$ $\mathrm{Nb}_{2} \mathrm{O}_{5} /$ graphene composite paper coupled with AC cathode delivered a high energy density of $47 \mathrm{~W} \mathrm{~h} \mathrm{~kg}^{-1}$ and power density of $18 \mathrm{KW} \mathrm{kg}^{-1}$ (Fig. 7h and 7i) [87]. Furthermore, $\mathrm{Nb}_{2} \mathrm{O}_{5}$ may also work as a catalytic 
material to enhance the capacitive capability of many other transition-metal oxides for flexible hybrid supercapacitors via boosting the redox reaction [133]. Song et al. further increased the mass content of $\mathrm{Nb}_{2} \mathrm{O}_{5}$ up to $93.5 \mathrm{wt} \%$ in the binder-free graphene hybrid electrode. Such long- $\mathrm{Nb}_{2} \mathrm{O}_{5}$-nanowires/rGO paper with shortened solid-state ion diffusion length and enhanced conductivity demonstrated an elevated voltage $(4.0 \mathrm{~V})$ and an improved energy density being a binder-free electrode or in a flexible Li-HSCs (106 Wh $\mathrm{kg}^{-1}$ at $580 \mathrm{~W} \mathrm{~kg}^{-1}$ ) [48]. Liu et al. designed an in-plane assembled $\mathrm{T}-\mathrm{Nb}_{2} \mathrm{O}_{5}$ nanorod film anode with highrate $\mathrm{Li}^{+}$intercalation for a flexible Li-HSCs (Fig. 8a) [18]. This binder-/additive-free hybrid film, fabricated via the direct growth of $\mathrm{T}-\mathrm{Nb}_{2} \mathrm{O}_{5}$ nanorods ( $\sim 100 \mathrm{~nm}$ in length and $20 \mathrm{~nm}$ in diameter, Fig. $\left.8 \mathrm{~b}-\mathrm{d}\right)$ on flexible carbon cloth by a facile hydrothermal process and subsequent annealing treatment, exhibited high specific capacity ( $220 \mathrm{~mA} \mathrm{~h} \mathrm{~g}^{-1}$ at $1 \mathrm{C}$ ), excellent rate capability (a $\sim 73 \%$ retention rate when increased from 0.5 to $20 \mathrm{C}$ ) and good cycling stability (>2,500 cycles). Kinetic analysis revealed that the high-rate performance was mainly attributed to the excellent in-plane assembly of interconnected single-crystalline $\mathrm{Nb}_{2} \mathrm{O}_{5}$ nanorods (with two sets of interplanar spacing, i.e., 0.927 and $0.393 \mathrm{~nm}$, elongated along [001] direction) on the robust porous current collector, ensuring the fast electron transport, facile $\mathrm{Li}^{+}$ion migration, and greatly reduced ion-diffusion length. When coupled with commercial activated carbon cathode, the flexible Li-HSCs could deliver both high gravimetric and high volumetric energy/power densities $\left(95.6 \mathrm{Wh} \mathrm{kg}^{-1}\right.$ / $5351 \mathrm{~W} \mathrm{~kg}^{-1} ; 6.7 \mathrm{~mW} \mathrm{~h} \mathrm{~cm}^{-3} / 375 \mathrm{~mW} \mathrm{~cm}^{-3}$ ), surpassing the previously reported typical Li-intercalation electrode-based Li-HSCs. Due to the enhanced mechanical strength of flexible electrode, it kept good electrochemical performance even upon serious bending deformations $\left(30^{\circ}-180^{\circ}\right)$ (Fig. 8e) [18]. In addition, for miniaturized supercapacitors or microsupercapacitors, the atomic layer deposition (ALD) method is an effective approach to fabricate $\mathrm{Nb}_{2} \mathrm{O}_{5}$-based on-chip micro-devices for extended application including Internet of Things (IoT) and wireless sensor network fields. By tuning the ALD times, the electrode thickness and areal capacity can be well controlled [134]. 

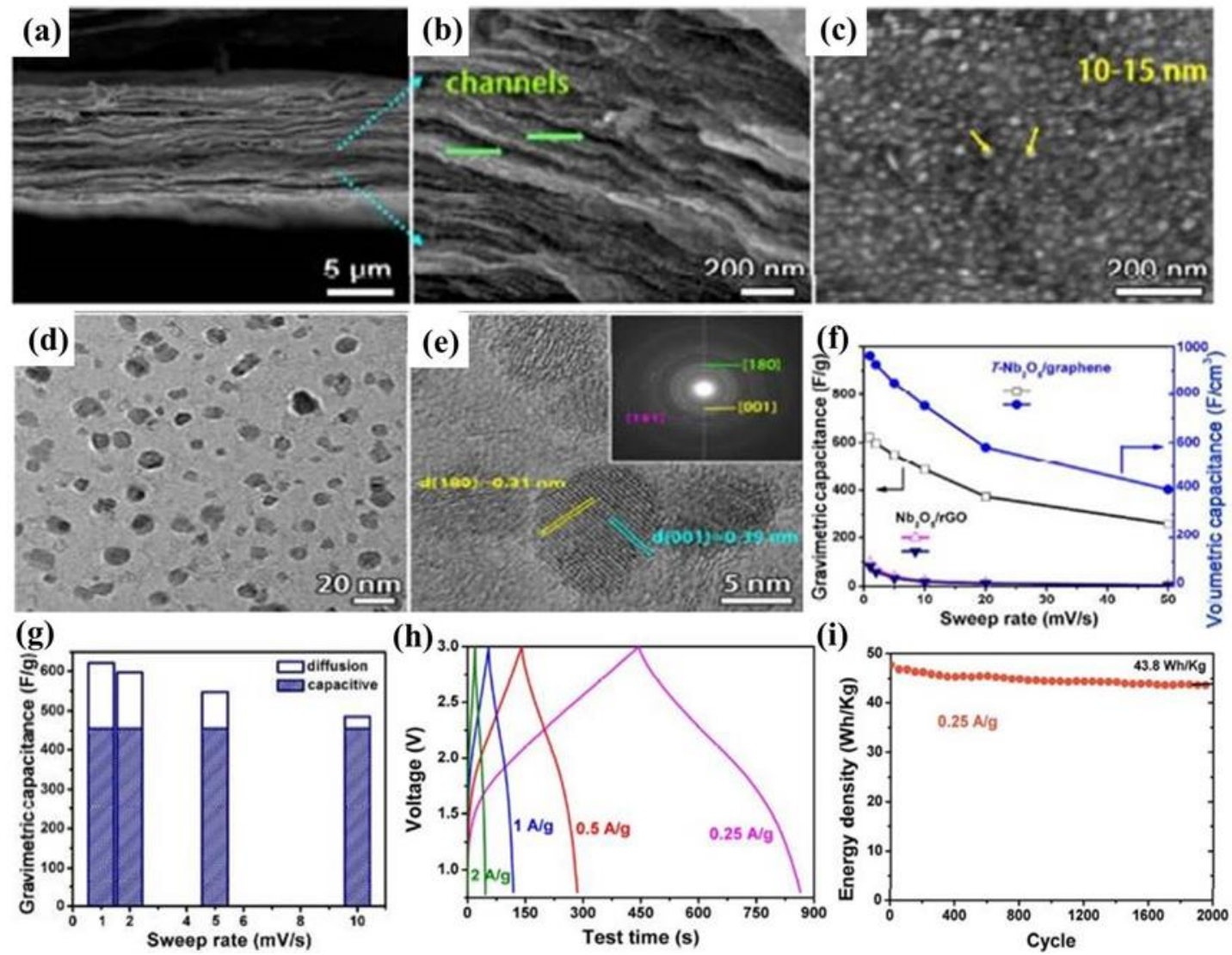

Fig. 7 (a-c) Cross-sectional and top-view SEM images of T- $\mathrm{Nb}_{2} \mathrm{O}_{5} /$ graphene composite papers. (d) TEM image and (e) HR-TEM and electron diffraction pattern of $\mathrm{T}-\mathrm{Nb}_{2} \mathrm{O}_{5} /$ graphene. (f) Plotting of capacitance versus sweep rate, $\left(\mathrm{g}\right.$ ) capacitive contribution of $\mathrm{T}-\mathrm{Nb}_{2} \mathrm{O}_{5} /$ graphene composite papers. (h) GCD curves, and (i) cycling performance of the $\mathrm{T}-\mathrm{Nb}_{2} \mathrm{O}_{5} /$ graphene//AC asymmetric supercapacitor. (Reproduced with permission [87]. Copyright 2015, American Chemical Society.) 

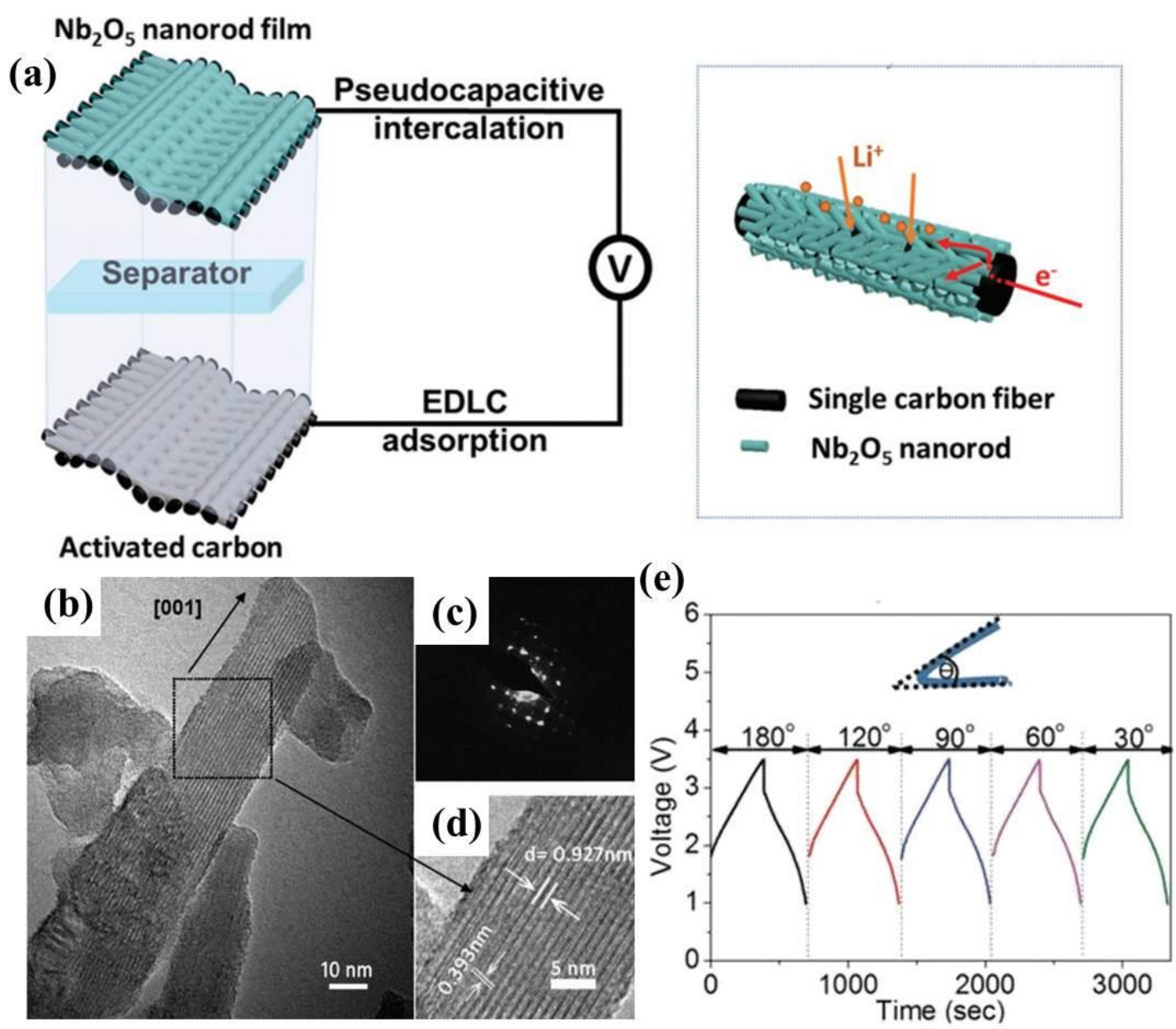

Fig. 8 (a) Schematic illustration of a Li-HSCs device configuration and the advantage of electrochemical kinetics of the in-plane assembled $\mathrm{Nb}_{2} \mathrm{O}_{5}$ nanorod film. (b-d) TEM images and SAED pattern of the nanorods from the $\mathrm{Nb}_{2} \mathrm{O}_{5}-600$ film. (e) Charge/discharge curves of the hybrid Li-HSCs at different bending angles. (Reproduced with permission [18]. Copyright 2017, WILEY-VCH.)

Introducing oxygen-deficiency may improve the electrical conductivity of stoichiometric $\mathrm{Nb}_{2} \mathrm{O}_{5}$ from

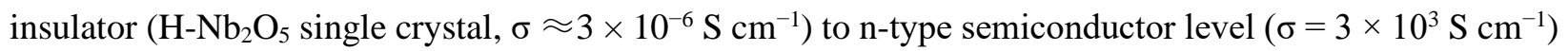
[135]. For example, the $\mathrm{H}_{2}$ treatment can significantly improve the electronic conductivity with enhanced rate capabilities (viz. Li storage kinetics) along with the changed bulk morphology and crystal structure [68]. Surface nitrogenization also provides a new opportunity to boost the electronic conductivity and performance for hybrid electrochemical capacitors [118]. The $\mathrm{Nb}_{2} \mathrm{O}_{5}$-based electrodes are characterized by faradaic and capacitive profiles, viz., showing respective contributions of faradaic and EDLC charge 
storage mechanisms. The transition from the faradaic to capacitive regime is caused by $\mathrm{Li}^{+}$starvation at the electrode/electrolyte interface (due to electrostatic repulsion) and formation of anionic electric double layer [136]. Moreover, the higher crystallinity in $\mathrm{Nb}_{2} \mathrm{O}_{5}$-based material can enhance the electronic conductivity and the transport properties for lithium intercalation. The electrode thickness can be controlled to strike a balance for the optimum performance between maximizing lithium intercalation and minimizing potential drop [136]. For the doping, e.g., by Ti, although the pseduocapacitive lithium storage is not affected by Ti doping, the Ti doped $\mathrm{T}-\mathrm{Nb}_{2} \mathrm{O}_{5}$ exhibited better long-term cycling stability due to the reduced charge transfer resistance and enhanced electronic conductivity during $\mathrm{Li}^{+}$insertion [112]. The related electrochemical performance had been summarized and demonstrated in Table 1 as below.

\begin{tabular}{|c|c|c|c|c|c|}
\hline Materials & $\begin{array}{l}\text { Voltage } \\
\text { (V) }\end{array}$ & $\begin{array}{c}\text { Energy } \\
\text { density } \\
\left(\mathrm{W} \mathrm{h} \mathrm{kg}^{-1}\right)\end{array}$ & $\begin{array}{c}\text { Power } \\
\text { density } \\
\left(\mathrm{kW} \mathrm{kg}^{-1}\right)\end{array}$ & $\begin{array}{l}\text { Cycle life } \\
\text { (capacitance } \\
\text { retention/cycles) }\end{array}$ & Year/Ref. \\
\hline \multirow{2}{*}{$\begin{array}{c}\mathrm{T}-\mathrm{Nb}_{2} \mathrm{O}_{5} \text { quantum dots/ } \\
\text { MOF derived N-doped carbon } \\
\text { (NQD-NC//AC) }\end{array}$} & $0.5-3.0$ & 51.4 & 8.75 & $85 \% / 4,500$ & \multirow[b]{2}{*}{$2016 /[77]$} \\
\hline & $0.5-4.0$ & 76.9 & 11.25 & $82 \% / 3,000$ & \\
\hline $\begin{array}{l}\text { Porous carbon nanowebs/T-Nb } \mathrm{O}_{5} \\
\left(3 \mathrm{D}-\mathrm{CNW} / \mathrm{T}-\mathrm{Nb}_{2} \mathrm{O}_{5} / / \mathrm{ACN}\right)\end{array}$ & $0.5-3.3$ & 80 & 5.3 & $80 \% / 35,000$ & $2017 /[93]$ \\
\hline $\begin{array}{c}\text { Microporous pyropolymer } \\
\text { nanoplates/T-Nb } 2 \mathrm{O}_{5} \\
\left.\text { (M-PNP/T-Nb } 2 \mathrm{O}_{5} / / \mathrm{M}-\mathrm{PNP}\right)\end{array}$ & $0-3.5$ & 47.5 & 10 & $75 \% / 30,000$ & $2018 /[120]$ \\
\hline Mesoporous $\mathrm{Nb}_{2} \mathrm{O}_{5} /$ carbon & $1.0-3.0$ & 48 & 14.2 & $90 \% / 1,000$ & \multirow{2}{*}{$2014 /[1]$} \\
\hline$\left(\mathrm{m}-\mathrm{Nb}_{2} \mathrm{O}_{5}-\mathrm{C} / / \mathrm{AC}\right)$ & $1.0-3.5$ & 74 & 18.5 & $99 \% / 1,000$ & \\
\hline $\begin{array}{c}\text { Yolk-shell } \mathrm{Nb}_{2} \mathrm{O}_{5} \text { microspheres } \\
\left(\mathrm{YS}-\mathrm{Nb}_{2} \mathrm{O}_{5} / / \mathrm{AC}\right)\end{array}$ & $1.0-3.5$ & 173 & 10.8 & $98 \% / 1,000$ & $2019 /[123]$ \\
\hline $\begin{array}{c}\mathrm{T}-\mathrm{Nb}_{2} \mathrm{O}_{5} / \mathrm{C} \\
\left(\mathrm{T}-\mathrm{Nb}_{2} \mathrm{O}_{5} / \mathrm{C} / / \mathrm{CDC}\right)\end{array}$ & $0-3.5$ & 92 & 17.5 & $86 \% / 10,000$ & $2019 /[104]$ \\
\hline \multirow{2}{*}{$\begin{array}{c}\mathrm{T}-\mathrm{Nb}_{2} \mathrm{O}_{5} \text { nanowires/rGO } \\
\left(\mathrm{T}-\mathrm{Nb}_{2} \mathrm{O}_{5} / \mathrm{rGO} / / \mathrm{AC}\right)\end{array}$} & $0-3.0$ & 45.1 & 9.1 & $82 \% / 5,000$ & \multirow{2}{*}{$2018 /[95]$} \\
\hline & $0-4.0$ & $\begin{array}{c}70 \\
\left(60^{\circ} \mathrm{C}\right)\end{array}$ & $\begin{array}{c}14.7 \\
\left(60^{\circ} \mathrm{C}\right)\end{array}$ & $71.6 \% / 4,000$ & \\
\hline
\end{tabular}




\begin{tabular}{|c|c|c|c|c|c|}
\hline $\begin{array}{c}\mathrm{T}-\mathrm{Nb}_{2} \mathrm{O}_{5} / \mathrm{N}, \mathrm{S} \text {-doped graphene } \\
\left(\mathrm{T}-\mathrm{Nb}_{2} \mathrm{O}_{5} / \mathrm{NS}-\mathrm{G} / / \mathrm{AC}\right)\end{array}$ & $1.0-3.5$ & 69.2 & 9.17 & $95 \% / 3,000$ & $2018 /[100]$ \\
\hline $\begin{array}{c}\text { Flexible } \mathrm{T}-\mathrm{Nb}_{2} \mathrm{O}_{5} / \text { graphene paper } \\
\text { (T-Nb}{ }_{2} \mathrm{O}_{5} / \text { graphene//AC) }\end{array}$ & $0.8-3.0$ & 47 & 18 & $93 \% / 2,000$ & $2015 /[87]$ \\
\hline $\begin{array}{c}\text { Flexible long- } \mathrm{Nb}_{2} \mathrm{O}_{5} \text { nanowires/ } \\
\text { rGO paper } \\
\left(\mathrm{L}_{-} \mathrm{Nb}_{2} \mathrm{O}_{5} \mathrm{NW} / \mathrm{rGO} / / \mathrm{ACN}\right)\end{array}$ & $1.0-4.0$ & 106 & 14 & $100 \% / 1,000$ & $2016 /[48]$ \\
\hline $\begin{array}{c}\mathrm{T}-\mathrm{Nb}_{2} \mathrm{O}_{5} \text { nanorod film } \\
\text { (flexible } \mathrm{T}-\mathrm{Nb}_{2} \mathrm{O}_{5} / / \mathrm{AC} \text {, carbon } \\
\text { cloth substrate) }\end{array}$ & $1.0-3.5$ & $\begin{array}{c}95.6 \\
(6.7 \mathrm{~mW} \mathrm{~h} \\
\left.\mathrm{cm}^{-3}\right)\end{array}$ & $\begin{array}{c}5.35 \\
(375 \mathrm{~mW} \\
\left.\mathrm{cm}^{-3}\right)\end{array}$ & $87 \% / 1,000$ & $2018 /[18]$ \\
\hline
\end{tabular}

\section{Na-ion hybrid capacitors}

Sodium-ion hybrid supercapacitors (Na-HSCs) can also bridge the performance gap between batteries and supercapacitors, which have attracted considerable attention for high-energy and high-power energy storage systems [13-15, 137]. However, one of the major obstacles to developing Na-HSCs is the imbalance of kinetics from different charge storage mechanisms involved: rapid non-faradaic capacitive behavior from cathode and sluggish faradaic behavior from anode $[12,13]$. Properties of anode with high capacitance but kinetic limitation determine the Na-HSCs performance. Thus, to develop high-power Na-HSCs anode materials are of great importance and urgency.

Orthorhombic $\mathrm{Nb}_{2} \mathrm{O}_{5}\left(\mathrm{~T}_{-}-\mathrm{Nb}_{2} \mathrm{O}_{5}\right)$ has been emerging as a promising anode material for $\mathrm{Na}-\mathrm{HSCs}$ due to its superior pseudocapacitive feature compared to carbonaceous materials, as it occurs not only on or near the surface but also in the bulk, but it suffers from intrinsically low electrical conductivity $[14,15,57]$. Nanostructure engineering is an efficient way to improve surface area, electrode-electrolyte interface area and electrochemical kinetics [138]. Li et al. designed a self-assembled structure comprised of $\mathrm{Nb}_{2} \mathrm{O}_{5}$ nanosheets (Fig. 9a-d) via a facile hydrothermal method with controlled reaction kinetics. When used as an anode in hybrid sodium ion capacitor with peanut-shell-derived carbon (PSC) cathode, $\mathrm{Nb}_{2} \mathrm{O}_{5}$ nanosheets with favorable architecture showed exceptional sodium ion storage property (Fig. 9e and 9f). The resulting $\mathrm{Nb}_{2} \mathrm{O}_{5}$ nanosheets//PSC hybrid demonstrated an exceptionally high energy density $\left(43.2 \mathrm{Wh} \mathrm{kg}^{-1}\right)$ and high 
power density $\left(5760 \mathrm{~W} \mathrm{~kg}^{-1}\right)$, as well as a long and stable cycle life (capacity retention: $\sim 80 \%$ at $1280 \mathrm{~mA}$ $\mathrm{g}^{-1}$ after 3000 cycles) (Fig. 9g and h) [57].

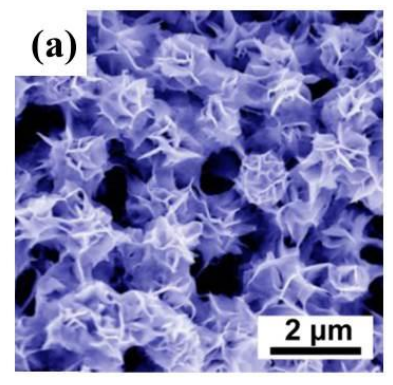

(e)

$\sum_{3}^{2}$
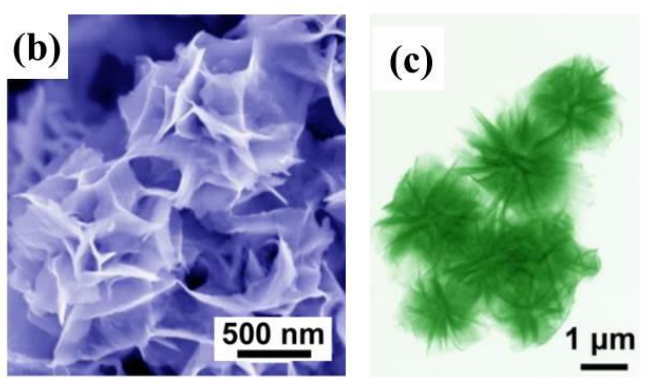

(d)

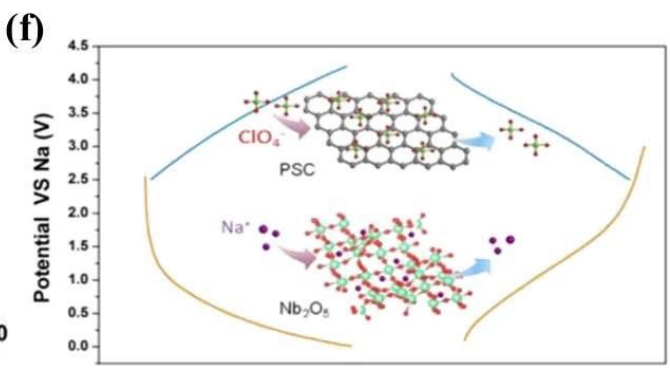

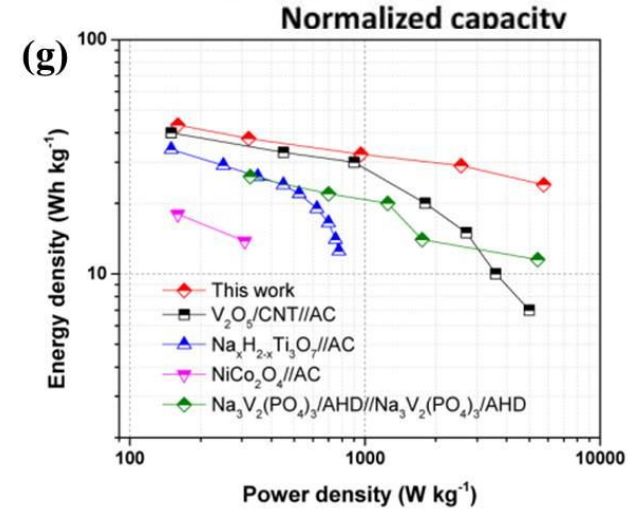

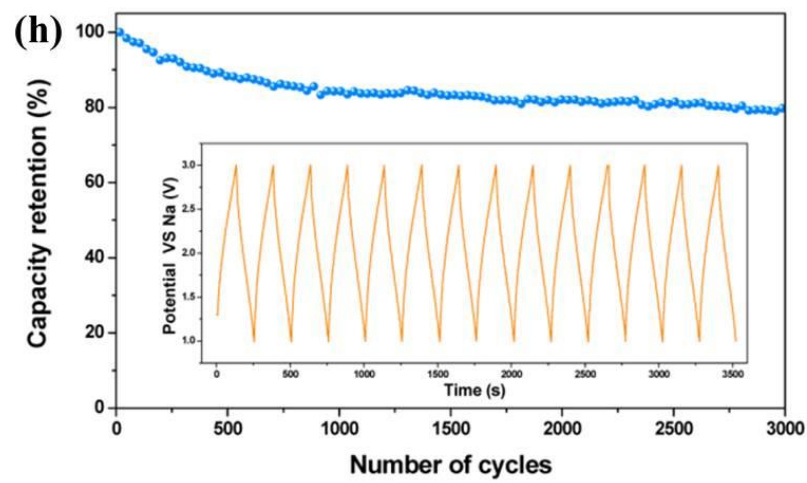

Fig. 9 ( $a$ and b) FESEM images and (c and d) TEM images of the self-assembled flower-like $\mathrm{Nb}_{2} \mathrm{O}_{5}$ structure, indicating the emanative character for the growth of $\mathrm{Nb}_{2} \mathrm{O}_{5}$ nanosheets. (e) Voltage profiles of as-prepared $\mathrm{Nb}_{2} \mathrm{O}_{5}$ nanosheets in different depths of charge-discharge. (f) Electrochemical evaluation of the $\mathrm{Nb}_{2} \mathrm{O}_{5}$ nanosheets//PSC Na-HSCs via voltage range illustration. (g) Ragone plot of $\mathrm{Nb}_{2} \mathrm{O}$ nanosheets//PSC Na-HSCs, in comparison with other reported results. (h) Long-term cycling performance of the $\mathrm{Nb}_{2} \mathrm{O}_{5}$ nanosheets//PSC Na-HSCs (at $1.28 \mathrm{~A} \mathrm{~g}^{-1}$ ). The inset shows the charge-discharge curves tested at a current density of $0.48 \mathrm{~A} \mathrm{~g}^{-1}$. (Reproduced with permission [57]. Copyright 2016, American Chemical Society.) 
Alternatively, the incorporation of carbon components into $\mathrm{Nb}_{2} \mathrm{O}_{5}$-based electrodes can achieve reasonably high electrochemical performance and even in flexible Na-HSCs devices $[13,15,62,139$, 140]. For example, Lee and coworkers synthesized a series of nanocomposites comprised of $\mathrm{Nb}_{2} \mathrm{O}_{5} @ \mathrm{C}$ core-shell nanoparticles $(\sim 13 \mathrm{~nm})$ and $\mathrm{rGO}$ at various weight ratios [12]. The $\mathrm{Nb}_{2} \mathrm{O}_{5} @ \mathrm{C} / \mathrm{rGO}-50$ showed highly reversible capacity $\left(285 \mathrm{~mA} \mathrm{~h} \mathrm{~g}^{-1}\right.$ at $\left.25 \mathrm{~mA} \mathrm{~g}^{-1}\right)$ and superior rate capability $\left(110 \mathrm{~mA} \mathrm{~h} \mathrm{~g}^{-1}\right.$ at 3 $\mathrm{A} \mathrm{g}^{-1}$ ) in the potential range of 0.01-3.0 $\mathrm{V}$ (vs. Na/Na+ ${ }^{+}$. The $\mathrm{Na}-\mathrm{HSCs}$ using $\mathrm{Nb}_{2} \mathrm{O}_{5} @ \mathrm{C} / \mathrm{rGO}-50$ as anode and commercial activated carbon (MSP-20) as cathode could deliver high energy/power densities (76 $\mathrm{W} \mathrm{h} \mathrm{kg}-1$ and $20.8 \mathrm{~kW} \mathrm{~kg}^{-1}$ ) with a stable cycle life in the potential range of $1.0-4.3 \mathrm{~V}$. It demonstrates promising possibilities for their application as high-power anode materials for Na-HSCs. To further enhance the performance especially high-rate capabilities, Wang et al. exploited an in-situ encapsulation strategy to directly grow ultrathin graphene shells over T-Nb${ }_{2} \mathrm{O}_{5}$ nanowires $\left(\mathrm{Gr}-\mathrm{Nb}_{2} \mathrm{O}_{5}\right.$ composites, Fig. 10a-c) by plasma-enhanced chemical vapor deposition (PECVD), targeting a highly conductive anode material for Na-HSCs [15]. The few-layered graphene capsulated 1D structure with sufficient and high tunable topological defects was endowed with excellent electron conductivity and facile electrolyte penetration/ $\mathrm{Na}^{+}$ion transport, guaranteeing rapid pseudocapacitive processes at the $\mathrm{Nb}_{2} \mathrm{O}_{5} /$ electrolyte interface. The $\mathrm{Gr}-\mathrm{Nb}_{2} \mathrm{O}_{5}$ composites exhibited remarkable sodium storage property, delivering a high reversible capacity $\left(285 \mathrm{mAh} \mathrm{g}^{-1}\right.$ at $0.25 \mathrm{C}$ and an ultrastable high-rate capability of $\sim 130 \mathrm{mAh} \mathrm{g}^{-1}$ at $20 \mathrm{C}$, Fig. 10d). The Na-HSCs full cell comprising $\mathrm{Gr}-\mathrm{Nb}_{2} \mathrm{O}_{5}$ anode and activated carbon (AC) cathode could deliver high energy/power densities (112.9 $\mathrm{Wh} \mathrm{kg}^{-1} / 80.1 \mathrm{~W} \mathrm{~kg}^{-1}$ and 62.2 $\mathrm{Wh} \mathrm{kg}^{-1} / 5330 \mathrm{~W} \mathrm{~kg}^{-1}$ ) with a stable cycle life (over 1,500 cycles) and a high Coulombic efficiency over $97.1 \%$ in the potential range of 1.0-4.3 V (Fig. 10e). Furthermore, the proof-of-concept flexible Na-HSCs devices with favorable mechanical robustness have manifested favorable electrochemical performance under different bending conditions (Fig. 10f) [15]. The sodium storage performance may be further enhanced by doping nitrogen into graphene because of the improved electronic conductivity and surface wettability, as well as the decreased energy barriers for $\mathrm{Na}^{+}$ion penetration, which is 
promising for a highly efficient $\mathrm{Nb}_{2} \mathrm{O}_{5}$-based energy storage system [14]. To achieve rapid redox kinetics together with flexible features, Li et al. fabricated large-area hybrid networks of mesoporous T$\mathrm{Nb}_{2} \mathrm{O}_{5}$ /carbon nanofiber (CNF) via electrospinning and in-situ $\mathrm{SiO}_{2}$-etching (Fig. 11a) [140]. These mesoporous multifunctional hybrid films were mechanically flexible and structurally stable without using any additives, binders, or current collectors, which efficiently increased the $\mathrm{Na}^{+}$-storage performance including excellent rate capabilities $\left(287 \mathrm{~mA} \mathrm{~h} \mathrm{~g}^{-1}\right.$ at $0.5 \mathrm{C}$, and $172 \mathrm{~mA} \mathrm{~h} \mathrm{~g}^{-1}$ up to 150 C) and outstanding cycling stability (a 94\% retention rate after 10,000 cycles at $100 \mathrm{C}$ ). The constructed flexible Na-HSCs device based on free-standing $\mathrm{m}-\mathrm{Nb}_{2} \mathrm{O}_{5} / \mathrm{CNF}$ anode and graphene framework/mesoporous CNF ( $\mathrm{GF} / \mathrm{mCNF}$ ) cathode could deliver both high energy density (124 $\mathrm{Wh} \mathrm{kg}^{-1}$ ) and impressive power densities (e.g. an ultrahigh power density of $60 \mathrm{~kW} \mathrm{~kg}^{-1}$ at $55 \mathrm{Wh} \mathrm{kg}^{-1}$ based on the total weight of active materials), as well as high volumetric energy and power densities (11.2 $\mathrm{mW} \mathrm{h}$ $\mathrm{cm}^{-3}, 5.4 \mathrm{~W} \mathrm{~cm}^{-3}$ ) based on the full device (Fig. 11b), which holds great promise in a wide variety of applications for flexible electronics. 

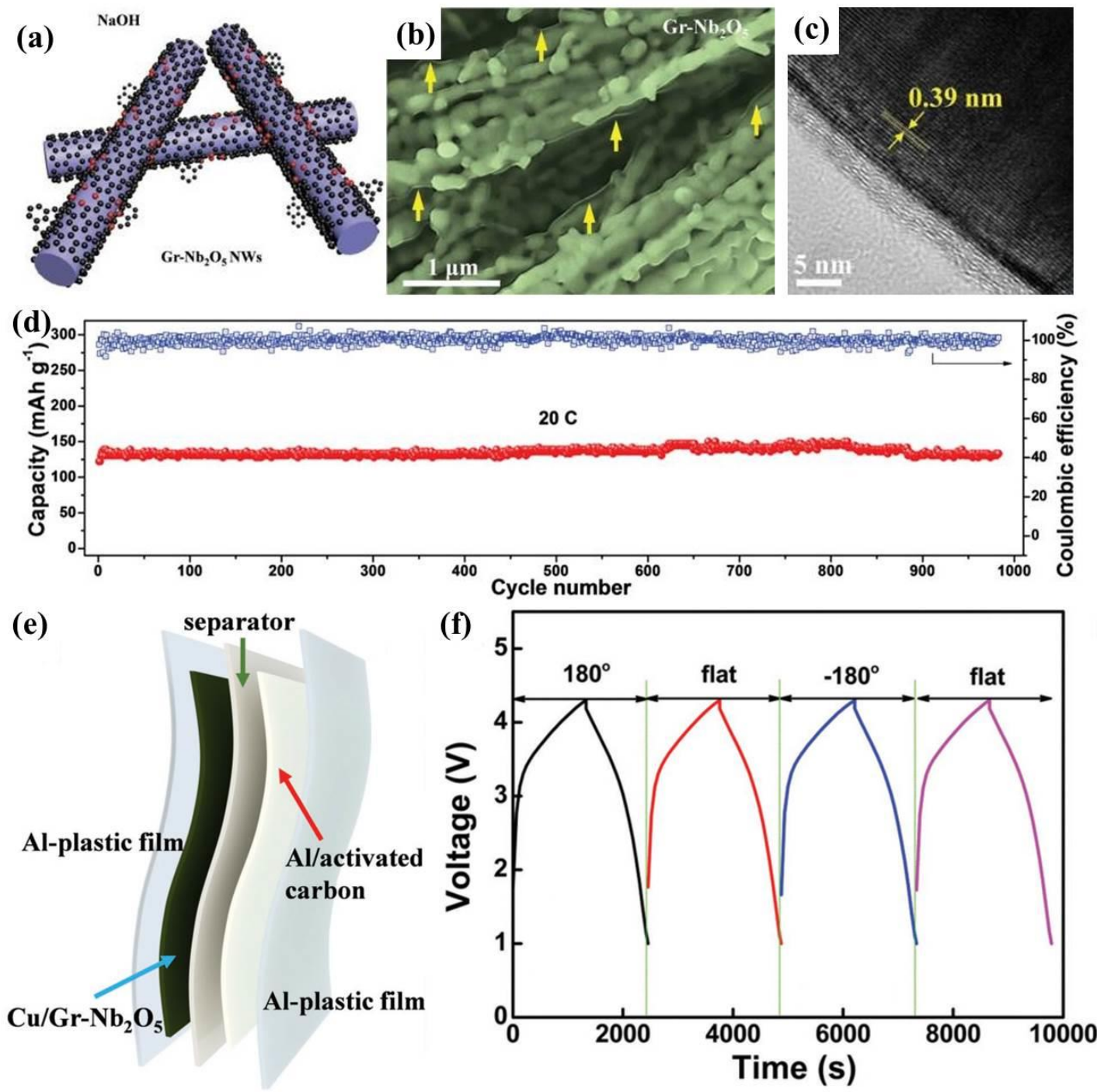

Fig. 10 (a) Schematic illustration of the as-prepared $\mathrm{Gr}_{-}-\mathrm{Nb}_{2} \mathrm{O}_{5} \mathrm{NWs}$ via in-situ graphene capsulation of $T$ $\mathrm{Nb}_{2} \mathrm{O}_{5}$ nanowires, and the corresponding (b) SEM image of (c) TEM image. (d) Long-term electrochemical cycling of the $\mathrm{Gr}-\mathrm{Nb}_{2} \mathrm{O}_{5}$ electrode at $20 \mathrm{C}$ rate. (e) Schematic illustration of a bendable $\mathrm{Gr}^{-} \mathrm{Nb}_{2} \mathrm{O}_{5} / / \mathrm{AC} \mathrm{Na}-$ HSCs device. (f) Galvanostatic charge/discharge profile of the bendable Na-HSCs full cell at different bending angles over a potential range of 1.0-4.3 V vs. Na/Na+ . (Reproduced with permission [15]. Copyright 2018, WILEY-VCH.) 


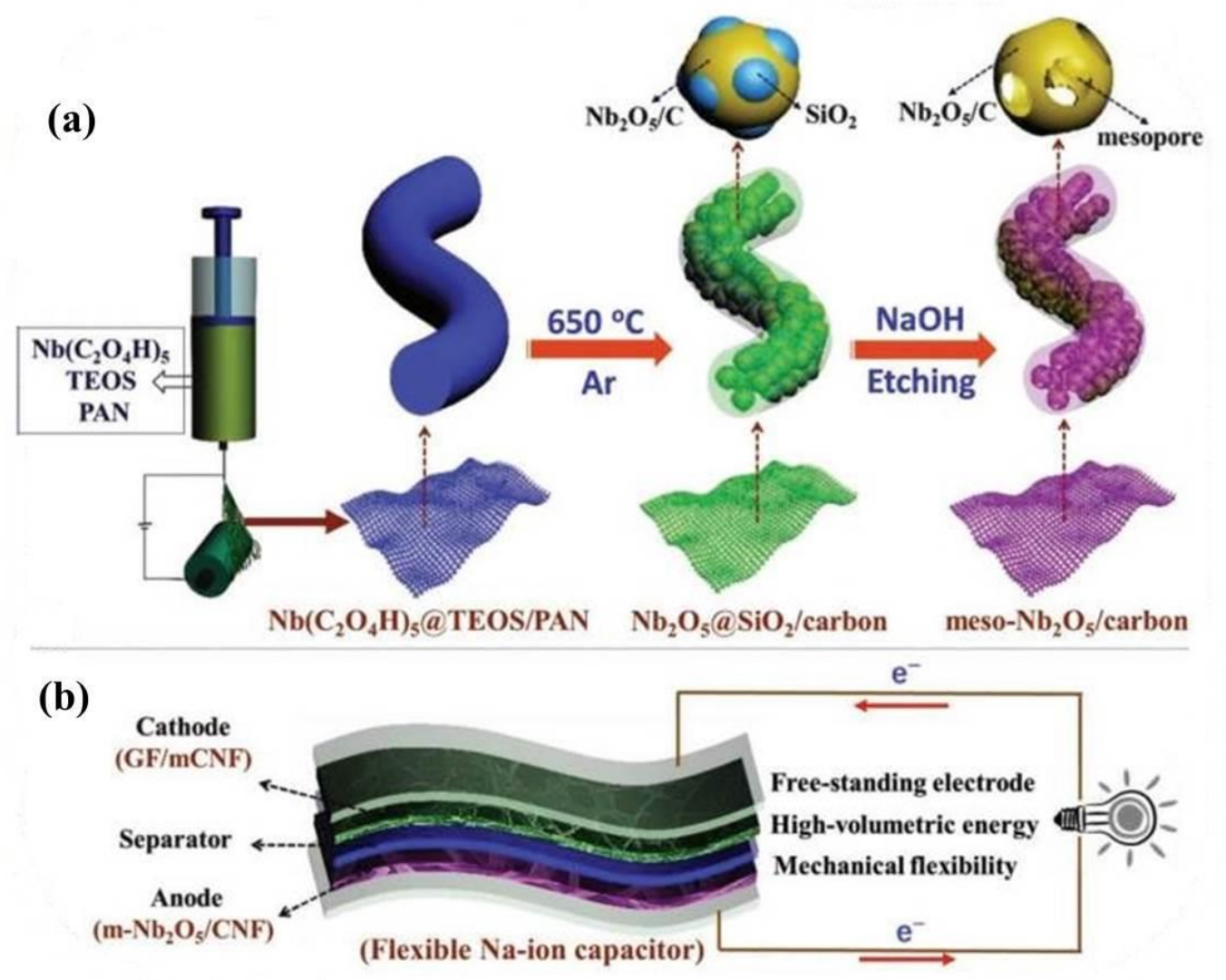

Fig. 11 Schematic illustration of (a) the fabrication of flexible m-Nb $\mathrm{O}_{5} / \mathrm{CNF}$ films and (b) the flexible $\mathrm{Na}$-ion capacitor device made from an $\mathrm{m}-\mathrm{Nb}_{2} \mathrm{O}_{5} / \mathrm{CNF}$ cathode and a $\mathrm{GF} / \mathrm{mCNF}$ anode. (Reproduced with permission [140]. Copyright 2019 WILEY-VCH.)

\section{Conclusion and Perspectives}

Layer-structured $\mathrm{T}-\mathrm{Nb}_{2} \mathrm{O}_{5}$ and its analogues, e.g., layered $\mathrm{TiNb}_{2} \mathrm{O}_{7}$ with unique properties have offered a greatly improved performance including high-rate capability and excellent cycle performance by taking advantage of their intrinsic structural merits. The theoretical calculations and experimental results demonstrate that the fast Li-ion intercalation in most of $\mathrm{Nb}$-based oxides is controlled by pseudocapcitive mechanism. They all have the similar features and suffer from poor electrical conductivity, hindering their electrochemical energy storage applications. Approaches such as nanostructurization, hybridization, 
composition and structure/architecture optimization, and electrode design have been applied to enhance rate and cycling performances of Nb-based oxides. However, some problems still remain to be solved for future storage applications such as LIBs, NIBs, HSCs. The use of Nb-based oxides in Na-HSCs is limited compared with Li-HSCs, due to the limited insertion hosts for larger size Na cations than Li.

Different from the conventional redox-active materials with pseudocapacitive charge storage that are based on faradaic charge-transfer reactions occurring at the surface or near-surface, $\mathrm{Nb}_{2} \mathrm{O}_{5}$ shows intrinsic intercalation pseudocapactitance with no semi-infinite diffusion limitations within specific planes in the 2D orthorhombic structure that contributes to fast $\mathrm{Li}^{+}$storage and facilitates the high-performance electrode design for hybrid electrochemical cell [54].

Layer-structured niobium oxides-based polymorphs with a crystalline network that offer twodimensional transport pathways with little structural change on the intercalation can take the advantages of high-rate intercalation pesedocapacitance with no limitations on solid-state diffusion (viz., charge-storage capacity mostly independent of rate). They are promising materials for high power and high energy density electrochemical energy storage devices [51]. For hybrid supercapcitors (HSCs), extensive efforts have been made to develop novel electrode materials. However, some other critical issues need to be effectively addressed including the kinetic imbalance between two electrodes to be effectively addressed including the kinetic imbalance between two electrodes to realize satisfactory energy and power densities as well as cycling stability.

Reducing active particles to nanoscale dimensions are frequently adopted to compensate the relatively slow solid-state ionic diffusion and to enable rapid charging and high power, but it is usually accompanied with the detriment of volumetric packing density and cost. The incorporation of cost-effective conductive agents such as graphene with niobium oxides is a most promising way to enhance the electrical conductivity and structural stability as well as achieve freestanding flexibility for flexible or wearable electronic devices. 2D MXenes with bifunctionality of active material (e.g. high energy-storage capability and 
pseudocapacitance) and higher conductivity are another ideal substrate or framework for layered niobium oxides. Generally, the synergistic effects between two intimately integrated layered structures intrinsically enhance the overall performances of HSCs for high energy and power densities. The doped or bimetallic niobium-based oxides such as niobium tungsten oxides, titanium niobium oxides with improved conductivity (e.g., ion diffusion coefficient and charge transfer efficiency), high capacity and excellent chemical durability (even in strong acidic solution) are expected to be an alternative for high-power applications, fast-charging devices in minutes, and even all-solid-state energy storage systems.

The performance improvement of HSCs depends on not only the intrinsic properties of individual electrode materials but also the compatibility in the full cell along with the desirable electrode design. Overall, "flat voltage" battery-type materials that undergo volume change during cycling are frequently lifetime limited, and thus more research on HSCs cathodes is needed; niobium oxides based materials are amongst the very few battery-type electrodes with demonstrated cycle life of 10,000 or 100,000 plus. In addition, simple device configuration and low fabrication cost are also major concerns for opening new solutions for energy storage devices that are sustainable, flexible and producible on a large scale.

\section{Acknowledgments}

This work was supported by the National Natural Science Foundation of China (Grant No. 51302079, 51403193), and the Natural Science Foundation of Hunan Province (Grant No. 2017JJ1008). 


\section{References}

[1] E. Lim, H. Kim, C. Jo, J. Chun, K. Ku, S. Kim, H.I. Lee, I.-S. Nam, S. Yoon, K. Kang, J. Lee, Advanced Hybrid Supercapacitor Based on a Mesoporous Niobium Pentoxide/Carbon as High-Performance Anode, ACS Nano, 8 (2014) 8968-8978.

[2] D. Han, J. Zhang, Z. Weng, D. Kong, Y. Tao, F. Ding, D. Ruan, Q.-H. Yang, Two-dimensional materials for lithium/sodium-ion capacitors, Mater. Today Energy, 11 (2019) 30-45.

[3] J. Ding, W. Hu, E. Paek, D. Mitlin, Review of Hybrid Ion Capacitors: From Aqueous to Lithium to Sodium, Chem. Rev., 118 (2018) 6457-6498.

[4] P. Han, G. Xu, X. Han, J. Zhao, X. Zhou, G. Cui, Lithium Ion Capacitors in Organic Electrolyte System: Scientific Problems, Material Development, and Key Technologies, Adv. Energy Mater., 8 (2018) 1801243.

[5] H. Wang, C. Zhu, D. Chao, Q. Yan, H.J. Fan, Nonaqueous Hybrid Lithium-Ion and Sodium-Ion Capacitors, Adv. Mater., 29 (2017) 1702093.

[6] B. Li, J. Zheng, H. Zhang, L. Jin, D. Yang, H. Lv, C. Shen, A. Shellikeri, Y. Zheng, R. Gong, J.P. Zheng, C. Zhang, Electrode Materials, Electrolytes, and Challenges in Nonaqueous Lithium-Ion Capacitors, Adv. Mater., 30 (2018) 1705670.

[7] Y. Shao, M.F. El-Kady, J. Sun, Y. Li, Q. Zhang, M. Zhu, H. Wang, B. Dunn, R.B. Kaner, Design and Mechanisms of Asymmetric Supercapacitors, Chem. Rev., 118 (2018) 9233-9280.

[8] C. Cui, H. Wang, M. Wang, X. Ou, Z. Wei, J. Ma, Y. Tang, Hollow Carbon Nanobelts Codoped with Nitrogen and Sulfur via a Self-Templated Method for a High-Performance Sodium-Ion Capacitor, Small, 15 (2019) 1902659.

[9] M. Wu, B. Xu, Y. Zhang, S. Qi, W. Ni, J. Hu, J. Ma, Perspectives in emerging bismuth electrochemistry, Chem. Eng. J., 381 (2020) 122558.

[10] W. Ni, L. Shi, Metal-Organic-Framework Composites as Proficient Cathodes for Supercapacitor Applications, Materials Research Foundations, 58 (2019) 177-238.

[11] W. Ni, J. Cheng, X. Li, G. Gu, L. Huang, Q. Guan, D. Yuan, B. Wang, Polymeric cathode materials of electroactive conducting poly (triphenylamine) with optimized structures for potential organic pseudocapacitors with higher cut-off voltage and energy density, RSC Adv., 5 (2015) 9221-9227.

[12] E. Lim, C. Jo, M.S. Kim, M.-H. Kim, J. Chun, H. Kim, J. Park, K.C. Roh, K. Kang, S. Yoon, J. Lee, High-Performance Sodium-Ion Hybrid Supercapacitor Based on $\mathrm{Nb}_{2} \mathrm{O}_{5} @$ Carbon Core-Shell Nanoparticles and Reduced Graphene Oxide Nanocomposites, Adv. Funct. Mater., 26 (2016) 3711-3719.

[13] Y. Wu, X. Fan, R.R. Gaddam, Q. Zhao, D. Yang, X. Sun, C. Wang, X.S. Zhao, Mesoporous niobium pentoxide/carbon composite electrodes for sodium-ion capacitors, J. Power Sources, 408 (2018) 82-90.

[14] L. She, Z. Yan, L. Kang, X. He, Z. Lei, F. Shi, H. Xu, J. Sun, Z.-H. Liu, $\mathrm{Nb}_{2} \mathrm{O}_{5}$ Nanoparticles Anchored on an N-Doped Graphene Hybrid Anode for a Sodium-Ion Capacitor with High Energy Density, ACS Omega, 3 (2018) 15943-15951.

[15] X. Wang, Q. Li, L. Zhang, Z. Hu, L. Yu, T. Jiang, C. Lu, C. Yan, J. Sun, Z. Liu, Caging $\mathrm{Nb}_{2} \mathrm{O}_{5}$ Nanowires in PECVD-Derived Graphene Capsules toward Bendable Sodium-Ion Hybrid Supercapacitors, Adv. Mater., 30 (2018) 1800963.

[16] M. Wu, W. Ni, J. Hu, J. Ma, NASICON-Structured $\mathrm{NaTi}_{2}\left(\mathrm{PO}_{4}\right)_{3}$ for Sustainable Energy Storage, NanoMicro Lett., 11 (2019) 44.

[17] L. Wang, X. Xie, K.N. Dinh, Q. Yan, J. Ma, Synthesis, characterizations, and utilization of oxygendeficient metal oxides for lithium/sodium-ion batteries and supercapacitors, Coord. Chem. Rev., 397 (2019) 138-167.

[18] B. Deng, T. Lei, W. Zhu, L. Xiao, J. Liu, In-Plane Assembled Orthorhombic $\mathrm{Nb}_{2} \mathrm{O}_{5}$ Nanorod Films with High-Rate $\mathrm{Li}^{+}$Intercalation for High-Performance Flexible Li-Ion Capacitors, Adv. Funct. Mater., 28 (2018) 1704330.

[19] Z. Wu, L. Li, J.-m. Yan, X.-b. Zhang, Materials design and system construction for conventional and new-concept supercapacitors, Adv. Sci., 4 (2017) 1600382. 
[20] D.P. Dubal, O. Ayyad, V. Ruiz, P. Gomez-Romero, Hybrid energy storage: the merging of battery and supercapacitor chemistries, Chem. Soc. Rev., 44 (2015) 1777-1790.

[21] V. Aravindan, M. Ulaganathan, S. Madhavi, Research progress in Na-ion capacitors, J. Mater. Chem. A, 4 (2016) 7538-7548.

[22] W. Zuo, R. Li, C. Zhou, Y. Li, J. Xia, J. Liu, Battery-Supercapacitor Hybrid Devices: Recent Progress and Future Prospects, Adv. Sci., 4 (2017) 1600539.

[23] Y. Yuan, C. Wang, K. Lei, H. Li, F. Li, J. Chen, Sodium-Ion Hybrid Capacitor of High Power and Energy Density, ACS central science, 4 (2018) 1261-1265.

[24] Z. Lin, E. Goikolea, A. Balducci, K. Naoi, P. Taberna, M. Salanne, G. Yushin, P. Simon, Materials for supercapacitors: When Li-ion battery power is not enough, Mater. Today, 21 (2018) 419-436.

[25] C. Zhang, M. Beidaghi, M. Naguib, M.R. Lukatskaya, M.-Q. Zhao, B. Dyatkin, K.M. Cook, S.J. Kim, B. Eng, X. Xiao, D. Long, W. Qiao, B. Dunn, Y. Gogotsi, Synthesis and Charge Storage Properties of Hierarchical Niobium Pentoxide/Carbon/Niobium Carbide (MXene) Hybrid Materials, Chem. Mater., 28 (2016) 3937-3943.

[26] Z. Wei, L. Wang, M. Zhuo, W. Ni, H. Wang, J. Ma, Layered Tin Sulfide and Selenide Anode Materials for Li- and Na-ion Batteries, J. Mater. Chem. A, 6 (2018) 12185-12214.

[27] J. Huang, Z. Wei, J. Liao, W. Ni, C. Wang, J. Ma, Molybdenum and tungsten chalcogenides for lithium/sodium-ion batteries: Beyond $\mathrm{MoS}_{2}$, J. Energy Chem., 33 (2019) 100-124.

[28] X.-Y. Yu, L. Yu, X.W. Lou, Metal Sulfide Hollow Nanostructures for Electrochemical Energy Storage, Adv. Energy Mater., 6 (2016) 1501333.

[29] H. Zhang, M. Chhowalla, Z. Liu, 2D nanomaterials: graphene and transition metal dichalcogenides, Chem. Soc. Rev., 47 (2018) 3015-3017.

[30] W. Choi, N. Choudhary, G.H. Han, J. Park, D. Akinwande, Y.H. Lee, Recent development of twodimensional transition metal dichalcogenides and their applications, Mater. Today, 20 (2017) 116-130.

[31] Y. Zhang, Q. Zhou, J. Zhu, Q. Yan, S.X. Dou, W. Sun, Nanostructured Metal Chalcogenides for Energy Storage and Electrocatalysis, Adv. Funct. Mater., 27 (2017) 1702317.

[32] B. Xu, S. Qi, P. He, J. Ma, Antimony- and Bismuth-Based Chalcogenides for Sodium-Ion Batteries, Chem. Asian J., 14 (2019) 2925-2937.

[33] D. Wu, C. Wang, M. Wu, Y. Chao, P. He, J. Ma, Porous bowl-shaped $\mathrm{VS}_{2}$ nanosheets/graphene composite for high-rate lithium-ion storage, J. Energy Chem., 43 (2020) 24-32.

[34] S. Qi, B. Xu, V.T. Tiong, J. Hu, J. Ma, Progress on iron oxides and chalcogenides as anodes for sodiumion batteries, Chem. Eng. J., 379 (2020) 122261.

[35] S. Qi, D. Wu, Y. Dong, J. Liao, C.W. Foster, C. O'Dwyer, Y. Feng, C. Liu, J. Ma, Cobalt-based electrode materials for sodium-ion batteries, Chem. Eng. J., 370 (2019) 185-207.

[36] X. Xie, M. Mao, S. Qi, J. Ma, ReS ${ }_{2}$-Based electrode materials for alkali-metal ion batteries, CrystEngComm, 21 (2019) 3755-3769.

[37] X. Zhu, J. Xu, Y. Luo, Q. Fu, G. Liang, L. Luo, Y. Chen, C. Lin, X.S. Zhao, $\mathrm{MoNb}_{12} \mathrm{O}_{33}$ as a new anode material for high-capacity, safe, rapid and durable $\mathrm{Li}^{+}$storage: structural characteristics, electrochemical properties and working mechanisms, J. Mater. Chem. A, 7 (2019) 6522-6532.

[38] R. Zheng, S. Qian, X. Cheng, H. Yu, N. Peng, T. Liu, J. Zhang, M. Xia, H. Zhu, J. Shu, FeNb ${ }_{11} \mathrm{O}_{29}$ nanotubes: Superior electrochemical energy storage performance and operating mechanism, Nano Energy, 58 (2019) 399-409.

[39] X. Zhang, S. Deng, Y. Zeng, M. Yu, Y. Zhong, X. Xia, Y. Tong, X. Lu, Oxygen Defect Modulated Titanium Niobium Oxide on Graphene Arrays: An Open-Door for High-Performance 1.4 V Symmetric Supercapacitor in Acidic Aqueous Electrolyte, Adv. Funct. Mater., 28 (2018) 1805618.

[40] S. Lou, X. Cheng, Y. Zhao, A. Lushington, J. Gao, Q. Li, P. Zuo, B. Wang, Y. Gao, Y. Ma, C. Du, G. Yin, X. Sun, Superior performance of ordered macroporous $\mathrm{TiNb}_{2} \mathrm{O}_{7}$ anodes for lithium ion batteries: Understanding from the structural and pseudocapacitive insights on achieving high rate capability, Nano Energy, 34 (2017) 15-25. 
[41] A.A. Lubimtsev, P.R.C. Kent, B.G. Sumpter, P. Ganesh, Understanding the origin of high-rate intercalation pseudocapacitance in $\mathrm{Nb}_{2} \mathrm{O}_{5}$ crystals, J. Mater. Chem. A, 1 (2013) 14951-14956.

[42] G. Park, N. Gunawardhana, C. Lee, S.-M. Lee, Y.-S. Lee, M. Yoshio, Development of a novel and safer energy storage system using a graphite cathode and $\mathrm{Nb}_{2} \mathrm{O}_{5}$ anode, J. Power Sources, 236 (2013) 145150.

[43] K. Brezesinski, J. Wang, J. Haetge, C. Reitz, S.O. Steinmueller, S.H. Tolbert, B.M. Smarsly, B. Dunn, T. Brezesinski, Pseudocapacitive Contributions to Charge Storage in Highly Ordered Mesoporous Group V Transition Metal Oxides with Iso-Oriented Layered Nanocrystalline Domains, J. Am. Chem. Soc., 132 (2010) 6982-6990.

[44] K.J. Griffith, K.M. Wiaderek, G. Cibin, L.E. Marbella, C.P. Grey, Niobium tungsten oxides for highrate lithium-ion energy storage, Nature, 559 (2018) 556-563.

[45] Q. Deng, Y. Fu, C. Zhu, Y. Yu, Niobium-Based Oxides Toward Advanced Electrochemical Energy Storage: Recent Advances and Challenges, Small, (2019) 1804884.

[46] L. Yan, X. Rui, G. Chen, W. Xu, G. Zou, H. Luo, Recent advances in nanostructured Nb-based oxides for electrochemical energy storage, Nanoscale, 8 (2016) 8443-8465.

[47] K. Kim, J. Hwang, H. Seo, H.-S. Kim, J.-H. Kim, Surface-controlled $\mathrm{Nb}_{2} \mathrm{O}_{5}$ nanoparticle networks for fast Li transport and storage, J. Mater. Sci., 54 (2019) 2493-2500.

[48] H. Song, J. Fu, K. Ding, C. Huang, K. Wu, X. Zhang, B. Gao, K. Huo, X. Peng, P.K. Chu, Flexible $\mathrm{Nb}_{2} \mathrm{O}_{5}$ nanowires/graphene film electrode for high-performance hybrid Li-ion supercapacitors, J. Power Sources, 328 (2016) 599-606.

[49] X. Wang, G. Li, Z. Chen, V. Augustyn, X. Ma, G. Wang, B. Dunn, Y. Lu, High-Performance Supercapacitors Based on Nanocomposites of $\mathrm{Nb}_{2} \mathrm{O}_{5}$ Nanocrystals and Carbon Nanotubes, Adv. Energy Mater., 1 (2011) 1089-1093.

[50] D. Chen, J.-H. Wang, T.-F. Chou, B. Zhao, M.A. El-Sayed, M. Liu, Unraveling the Nature of Anomalously Fast Energy Storage in T- $\mathrm{Nb}_{2} \mathrm{O}_{5}$, J. Am. Chem. Soc., 139 (2017) 7071-7081.

[51] V. Augustyn, J. Come, M.A. Lowe, J.W. Kim, P.-L. Taberna, S.H. Tolbert, H.D. Abruña, P. Simon, B. Dunn, High-rate electrochemical energy storage through $\mathrm{Li}^{+}$intercalation pseudocapacitance, Nat. Mater., 12 (2013) 518-522.

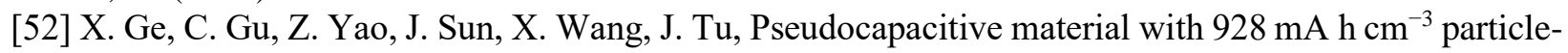
level volumetric specific capacity enabled by continuous phase-transition, Chem. Eng. J., 338 (2018) 211 217.

[53] H. Sun, L. Mei, J. Liang, Z. Zhao, C. Lee, H. Fei, M. Ding, J. Lau, M. Li, C. Wang, X. Xu, G. Hao, B. Papandrea, I. Shakir, B. Dunn, Y. Huang, X. Duan, Three-dimensional holey-graphene/niobia composite architectures for ultrahigh-rate energy storage, Science, 356 (2017) 599-604.

[54] J. Come, V. Augustyn, J.W. Kim, P. Rozier, P.-L. Taberna, P. Gogotsi, J.W. Long, B. Dunn, P. Simon, Electrochemical kinetics of nanostructured $\mathrm{Nb}_{2} \mathrm{O}_{5}$ electrodes, J. Electrochem. Soc., 161 (2014) A718-A725.

[55] G.-J. Park, D. Kalpana, A.K. Thapa, H. Nakamura, Y.-S. Lee, M. Yoshio, A novel hybrid supercapacitor using a graphite cathode and a niobium (V) oxide anode, Bull. Korean Chem. Soc., 30 (2009) 817-820.

[56] L. Wang, X. Bi, S. Yang, Partially Single-Crystalline Mesoporous $\mathrm{Nb}_{2} \mathrm{O}_{5}$ Nanosheets in between Graphene for Ultrafast Sodium Storage, Adv. Mater., 28 (2016) 7672-7679.

[57] H. Li, Y. Zhu, S. Dong, L. Shen, Z. Chen, X. Zhang, G. Yu, Self-Assembled $\mathrm{Nb}_{2} \mathrm{O}_{5}$ Nanosheets for High Energy-High Power Sodium Ion Capacitors, Chem. Mater., 28 (2016) 5753-5760.

[58] J. Ni, W. Wang, C. Wu, H. Liang, J. Maier, Y. Yu, L. Li, Highly Reversible and Durable Na Storage in Niobium Pentoxide through Optimizing Structure, Composition, and Nanoarchitecture, Adv. Mater., 29 (2017) 1605607.

[59] L. Yang, Y.-E. Zhu, J. Sheng, F. Li, B. Tang, Y. Zhang, Z. Zhou, T-Nb $\mathrm{O}_{5} / \mathrm{C}$ Nanofibers Prepared through Electrospinning with Prolonged Cycle Durability for High-Rate Sodium-Ion Batteries Induced by Pseudocapacitance, Small, 13 (2017) 1702588. 
[60] W. Shangguan, K. Inoue, Synthesis of silica-pillared layered titanium niobium oxide, Chem. Commun., (1998) 779-780.

[61] H. Li, L. Shen, J. Wang, S. Fang, Y. Zhang, H. Dou, X. Zhang, Three-dimensionally ordered porous $\mathrm{TiNb}_{2} \mathrm{O}_{7}$ nanotubes: a superior anode material for next generation hybrid supercapacitors, J. Mater. Chem. A, 3 (2015) 16785-16790.

[62] X. Zhang, J. Zhang, S. Kong, K. Zhu, J. Yan, K. Ye, G. Wang, K. Cheng, L. Zhou, D. Cao, A novel calendula-like $\mathrm{MnNb}_{2} \mathrm{O}_{6}$ anchored on graphene sheet as high-performance intercalation pseudocapacitive anode for lithium-ion capacitors, J. Mater. Chem. A, 7 (2019) 2855-2863.

[63] S. Li, J. Chen, X. Gong, J. Wang, P.S. Lee, Holey graphene-wrapped porous $\mathrm{TiNb}_{24} \mathrm{O}_{62}$ microparticles as high-performance intercalation pseudocapacitive anode materials for lithium-ion capacitors, NPG Asia Materials, 10 (2018) 406-416.

[64] J.H. Lee, H.-K. Kim, E. Baek, M. Pecht, S.-H. Lee, Y.-H. Lee, Improved performance of cylindrical hybrid supercapacitor using activated carbon/ niobium doped hydrogen titanate, J. Power Sources, 301 (2016) 348-354.

[65] L. Hu, L. Luo, L. Tang, C. Lin, R. Li, Y. Chen, $\mathrm{Ti}_{2} \mathrm{Nb}_{2 x} \mathrm{O}_{4+5 x}$ anode materials for lithium-ion batteries: a comprehensive review, J. Mater. Chem. A, 6 (2018) 9799-9815.

[66] X. Wang, C. Yan, J. Yan, A. Sumboja, P.S. Lee, Orthorhombic niobium oxide nanowires for next generation hybrid supercapacitor device, Nano Energy, 11 (2015) 765-772.

[67] S. Ahmed, M. Rafat, Effect of lithium and sodium salt on the performance of $\mathrm{Nb}_{2} \mathrm{O}_{5} / \mathrm{rGO}$ nanocomposite based supercapacitor, Mater. Res. Express, 5 (2018) 035512.

[68] K. Kim, M.-S. Kim, P.-R. Cha, S.H. Kang, J.-H. Kim, Structural Modification of Self-Organized Nanoporous Niobium Oxide via Hydrogen Treatment, Chem. Mater., 28 (2016) 1453-1461.

[69] L. Kong, X. Cao, J. Wang, W. Qiao, L. Ling, D. Long, Revisiting $\mathrm{Li}^{+}$intercalation into various crystalline phases of $\mathrm{Nb}_{2} \mathrm{O}_{5}$ anchored on graphene sheets as pseudocapacitive electrodes, J. Power Sources, 309 (2016) 42-49.

[70] S. Li, Q. Xu, E. Uchaker, X. Cao, G. Cao, Comparison of amorphous, pseudohexagonal and orthorhombic $\mathrm{Nb}_{2} \mathrm{O}_{5}$ for high-rate lithium ion insertion, CrystEngComm, 18 (2016) 2532-2540.

[71] K.J. Griffith, A.C. Forse, J.M. Griffin, C.P. Grey, High-Rate Intercalation without Nanostructuring in Metastable $\mathrm{Nb}_{2} \mathrm{O}_{5}$ Bronze Phases, J. Am. Chem. Soc., 138 (2016) 8888-8899.

[72] K. Kim, S.-G. Woo, Y.N. Jo, J. Lee, J.-H. Kim, Niobium oxide nanoparticle core-amorphous carbon shell structure for fast reversible lithium storage, Electrochim. Acta, 240 (2017) 316-322.

[73] Y. Zhao, X. Zhou, L. Ye, S. Chi Edman Tsang, Nanostructured $\mathrm{Nb}_{2} \mathrm{O}_{5}$ catalysts, Nano Rev., 3 (2012) 17631.

[74] R. Kodama, Y. Terada, I. Nakai, S. Komaba, N. Kumagai, Electrochemical and in situ XAFS-XRD investigation of $\mathrm{Nb}_{2} \mathrm{O}_{5}$ for rechargeable lithium batteries, J. Electrochem. Soc., 153 (2006) A583-A588.

[75] J.W. Kim, V. Augustyn, B. Dunn, The Effect of Crystallinity on the Rapid Pseudocapacitive Response of $\mathrm{Nb}_{2} \mathrm{O}_{5}$, Adv. Energy Mater., 2 (2012) 141-148.

[76] Z. Fan, J. Yan, T. Wei, L. Zhi, G. Ning, T. Li, F. Wei, Asymmetric Supercapacitors Based on Graphene/ $\mathrm{MnO}_{2}$ and Activated Carbon Nanofiber Electrodes with High Power and Energy Density, Adv. Funct. Mater., 21 (2011) 2366-2375.

[77] S. Liu, J. Zhou, Z. Cai, G. Fang, Y. Cai, A. Pan, S. Liang, $\mathrm{Nb}_{2} \mathrm{O}_{5}$ quantum dots embedded in MOF derived nitrogen-doped porous carbon for advanced hybrid supercapacitor applications, J. Mater. Chem. A, 4 (2016) 17838-17847.

[78] K. Tang, X. Mu, P.A. van Aken, Y. Yu, J. Maier, "Nano-Pearl-String" $\mathrm{TiNb}_{2} \mathrm{O}_{7}$ as Anodes for Rechargeable Lithium Batteries, Adv. Energy Mater., 3 (2013) 49-53.

[79] Q. Cheng, J. Liang, Y. Zhu, L. Si, C. Guo, Y. Qian, Bulk $\mathrm{Ti}_{2} \mathrm{Nb}_{10} \mathrm{O}_{29}$ as long-life and high-power Liion battery anodes, J. Mater. Chem. A, 2 (2014) 17258-17262.

[80] C. Lin, G. Wang, S. Lin, J. Li, L. Lu, $\operatorname{TiNb}_{6} \mathrm{O}_{17}$ : a new electrode material for lithium-ion batteries, Chem. Commun., 51 (2015) 8970-8973. 
[81] C. Yang, S. Deng, C. Lin, S. Lin, Y. Chen, J. Li, H. Wu, Porous $\mathrm{TiNb}_{24} \mathrm{O}_{62}$ microspheres as highperformance anode materials for lithium-ion batteries of electric vehicles, Nanoscale, 8 (2016) 1879218799.

[82] K. Ise, S. Morimoto, Y. Harada, N. Takami, Large lithium storage in highly crystalline $\mathrm{TiNb}_{2} \mathrm{O}_{7}$ nanoparticles synthesized by a hydrothermal method as anodes for lithium-ion batteries, Solid State Ionics, 320 (2018) 7-15.

[83] X. Wang, G. Shen, Intercalation pseudo-capacitive $\mathrm{TiNb}_{2} \mathrm{O}_{7} @$ carbon electrode for high-performance lithium ion hybrid electrochemical supercapacitors with ultrahigh energy density, Nano Energy, 15 (2015) 104-115.

[84] V. Aravindan, J. Sundaramurthy, A. Jain, P.S. Kumar, W.C. Ling, S. Ramakrishna, M.P. Srinivasan, S. Madhavi, Unveiling $\mathrm{TiNb}_{2} \mathrm{O}_{7}$ as an Insertion Anode for Lithium Ion Capacitors with High Energy and Power Density, ChemSusChem, 7 (2014) 1858-1863.

[85] X. Lu, Z. Jian, Z. Fang, L. Gu, Y.-S. Hu, W. Chen, Z. Wang, L. Chen, Atomic-scale investigation on lithium storage mechanism in $\mathrm{TiNb}_{2} \mathrm{O}_{7}$, Energy Environ. Sci., 4 (2011) 2638-2644.

[86] M. Catti, I. Pinus, K. Knight, Lithium insertion properties of $\mathrm{Li}_{\mathrm{x}} \mathrm{TiNb}_{2} \mathrm{O}_{7}$ investigated by neutron diffraction and first-principles modelling, J. Solid State Chem., 229 (2015) 19-25.

[87] L. Kong, C. Zhang, J. Wang, W. Qiao, L. Ling, D. Long, Free-Standing T-Nb $\mathrm{O}_{5} /$ Graphene Composite Papers with Ultrahigh Gravimetric/Volumetric Capacitance for Li-Ion Intercalation Pseudocapacitor, ACS Nano, 9 (2015) 11200-11208.

[88] L. Kong, X. Liu, J. Wei, S. Wang, B.B. Xu, D. Long, F. Chen, T-Nb ${ }_{2} \mathrm{O}_{5}$ nanoparticle enabled pseudocapacitance with fast Li-ion intercalation, Nanoscale, 10 (2018) 14165-14170.

[89] S. Ozkan, N.T. Nguyen, I. Hwang, A. Mazare, P. Schmuki, Highly Conducting Spaced $\mathrm{TiO}_{2} \mathrm{Nanotubes}$ Enable Defined Conformal Coating with Nanocrystalline $\mathrm{Nb}_{2} \mathrm{O}_{5}$ and High Performance Supercapacitor Applications, Small, 13 (2017) 1603821.

[90] G. Luo, H. Li, D. Zhang, L. Gao, T. Lin, A template-free synthesis via alkaline route for $\mathrm{Nb}_{2} \mathrm{O}_{5} /$ carbon nanotubes composite as pseudo-capacitor material with high-rate performance, Electrochim. Acta, 235 (2017) 175-181.

[91] R.M. Silva, B.S. Noremberg, N.H. Marins, J. Milne, I. Zhitomirsky, N.L.V. Carreño, Microwaveassisted hydrothermal synthesis and electrochemical characterization of niobium pentoxide/carbon nanotubes composites, J. Mater. Res., 34 (2019) 592-599.

[92] X. Wang, G. Li, R. Tjandra, X. Fan, X. Xiao, A. Yu, Fast lithium-ion storage of $\mathrm{Nb}_{2} \mathrm{O}_{5}$ nanocrystals in situ grown on carbon nanotubes for high-performance asymmetric supercapacitors, RSC Adv., 5 (2015) 41179-41185.

[93] M.Y. Song, N.R. Kim, H.J. Yoon, S.Y. Cho, H.-J. Jin, Y.S. Yun, Long-Lasting $\mathrm{Nb}_{2} \mathrm{O}_{5}-\mathrm{Based}$ Nanocomposite Materials for Li-Ion Storage, ACS Appl. Mater. Interfaces, 9 (2017) 2267-2274.

[94] J. Zhang, H. Chen, X. Sun, X. Kang, Y. Zhang, C. Xu, Y. Zhang, High Intercalation Pseudocapacitance of Free-Standing T- $\mathrm{Nb}_{2} \mathrm{O}_{5}$ Nanowires@ carbon Cloth Hybrid Supercapacitor Electrodes, J. Electrochem. Soc., 164 (2017) A820-A825.

[95] Y. Jiao, H. Zhang, H. Zhang, A. Liu, Y. Liu, S. Zhang, Highly bonded T- $-\mathrm{Nb}_{2} \mathrm{O}_{5} / \mathrm{rGO}$ nanohybrids for $4 \mathrm{~V}$ quasi-solid state asymmetric supercapacitors with improved electrochemical performance, Nano Res., 11 (2018) 4673-4685.

[96] L.P. Wang, L. Yu, R. Satish, J. Zhu, Q. Yan, M. Srinivasan, Z. Xu, High-performance hybrid electrochemical capacitor with binder-free $\mathrm{Nb}_{2} \mathrm{O}_{5} @$ graphene, RSC Adv., 4 (2014) 37389-37394.

[97] G. Ma, K. Li, Y. Li, B. Gao, T. Ding, Q. Zhong, J. Su, L. Gong, J. Chen, L. Yuan, B. Hu, J. Zhou, K. Huo, High-Performance Hybrid Supercapacitor Based on Graphene-Wrapped Mesoporous $\mathrm{T}_{-} \mathrm{Nb}_{2} \mathrm{O}_{5}$ Nanospheres Anode and Mesoporous Carbon-Coated Graphene Cathode, ChemElectroChem, 3 (2016) $1360-1368$.

[98] L. Kong, C. Zhang, S. Zhang, J. Wang, R. Cai, C. Lv, W. Qiao, L. Ling, D. Long, High-power and high-energy asymmetric supercapacitors based on $\mathrm{Li}^{+}$-intercalation into a $\mathrm{T}-\mathrm{Nb}_{2} \mathrm{O}_{5} /$ graphene pseudocapacitive electrode, J. Mater. Chem. A, 2 (2014) 17962-17970. 
[99] P. Arunkumar, A.G. Ashish, B. Babu, S. Sarang, A. Suresh, C.H. Sharma, M. Thalakulam, M.M. Shaijumon, $\mathrm{Nb}_{2} \mathrm{O}_{5}$ /graphene nanocomposites for electrochemical energy storage, RSC Adv., 5 (2015) 59997-60004.

[100] X. Jiao, Q. Hao, P. Liu, X. Xia, W. Lei, X. Liu, Facile synthesis of T- $\mathrm{Nb}_{2} \mathrm{O}_{5}$ nanosheets/nitrogen and sulfur co-doped graphene for high performance lithium-ion hybrid supercapacitors, Sci. China Mater., 61 (2018) 273-284.

[101] X. Jiao, Q. Hao, X. Xia, Z. Wu, W. Lei, Metal organic framework derived $\mathrm{Nb}_{2} \mathrm{O}_{5} @ \mathrm{C}$ nanoparticles grown on reduced graphene oxide for high-energy lithium ion capacitors, Chem. Commun., 55 (2019) 2692-2695.

[102] C. Zhang, R. Maloney, M.R. Lukatskaya, M. Beidaghi, B. Dyatkin, E. Perre, D. Long, W. Qiao, B. Dunn, Y. Gogotsi, Synthesis and electrochemical properties of niobium pentoxide deposited on layered carbide-derived carbon, J. Power Sources, 274 (2015) 121-129.

[103] S. Hemmati, G. Li, X. Wang, Y. Ding, Y. Pei, A. Yu, Z. Chen, 3D N-doped hybrid architectures assembled from $0 \mathrm{D} \mathrm{T}-\mathrm{Nb}_{2} \mathrm{O}_{5}$ embedded in carbon microtubes toward high-rate Li-ion capacitors, Nano Energy, 56 (2019) 118-126.

[104] H. Li, J. Chen, B. Yang, K. Wang, X. Zhang, T. Zhang, L. Zhang, W. Liu, X. Yan, Constructing surface-driven lithium ion storage structure for high performance hybrid capacitor, Electrochim. Acta, 299 (2019) 163-172.

[105] G. Luo, H. Li, L. Gao, D. Zhang, T. Lin, Porous structured niobium pentoxide/carbon complex for lithium-ion intercalation pseudocapacitors, Mater. Sci. Eng. B, 214 (2016) 74-80.

[106] J. Wang, H. Li, L. Shen, S. Dong, X. Zhang, $\mathrm{Nb}_{2} \mathrm{O}_{5}$ nanoparticles encapsulated in ordered mesoporous carbon matrix as advanced anode materials for Li ion capacitors, RSC Adv., 6 (2016) 71338-71344.

[107] L. Kong, C. Zhang, J. Wang, W. Qiao, L. Ling, D. Long, Nanoarchitectured $\mathrm{Nb}_{2} \mathrm{O}_{5}$ hollow, $\mathrm{Nb}_{2} \mathrm{O}_{5} @$ carbon and $\mathrm{NbO}_{2} @$ carbon Core-Shell Microspheres for Ultrahigh-Rate Intercalation Pseudocapacitors, Sci. Rep., 6 (2016) 21177.

[108] H. Yang, H. Xu, L. Wang, L. Zhang, Y. Huang, X. Hu, Microwave-Assisted Rapid Synthesis of SelfAssembled T- $\mathrm{Nb}_{2} \mathrm{O}_{5}$ Nanowires for High-Energy Hybrid Supercapacitors, Chem. Eur. J., 23 (2017) 42034209.

[109] D. Li, J. Shi, H. Liu, C. Liu, G. Dong, H. Zhang, Y. Yang, G. Lu, H. Wang, T-Nb ${ }_{2} \mathrm{O}_{5}$ embedded carbon nanosheets with superior reversibility and rate capability as an anode for high energy Li-ion capacitors, Sustainable Energy Fuels, 3 (2019) 1055-1065.

[110] K. Karthick, U. Nithiyanantham, S.R. Ede, S. Kundu, DNA Aided Formation of Aggregated $\mathrm{Nb}_{2} \mathrm{O}_{5}$ Nanoassemblies as Anode Material for Dye Sensitized Solar Cell (DSSC) and Supercapacitor Applications, ACS Sustainable Chem. Eng., 4 (2016) 3174-3188.

[111] S.H. Kang, C.-M. Park, J. Lee, J.-H. Kim, Electrochemical lithium storage kinetics of self-organized nanochannel niobium oxide electrodes, J. Electroanal. Chem., 746 (2015) 45-50.

[112] X. Wang, P.S. Lee, Titanium doped niobium oxide for stable pseudocapacitive lithium ion storage and its application in 3 V non-aqueous supercapacitors, J. Mater. Chem. A, 3 (2015) 21706-21712.

[113] L. Kong, C. Zhang, J. Wang, D. Long, W. Qiao, L. Ling, Ultrahigh intercalation pseudocapacitance of mesoporous orthorhombic niobium pentoxide from a novel cellulose nanocrystal template, Mater. Chem. Phys., 149-150 (2015) 495-504.

[114] J. Liu, I. Shakir, D.J. Kang, Lithium niobate nanoflakes as electrodes for highly stable electrochemical supercapacitor devices, Mater. Lett., 119 (2014) 84-87.

[115] S. Li, T. Wang, J. Lian, Y. Zhao, Y. Huang, J. Qiu, H. Xu, X. Zhang, H. Li, Pseudocapacitive

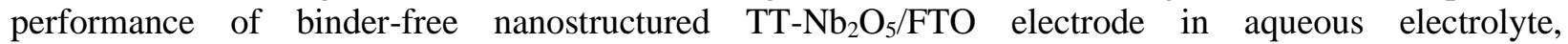
Nanotechnology, 30 (2018) 025401.

[116] F. Idrees, J. Hou, C. Cao, F.K. Butt, I. Shakir, M. Tahir, F. Idrees, Template-free synthesis of highly ordered 3D-hollow hierarchical $\mathrm{Nb}_{2} \mathrm{O}_{5}$ superstructures as an asymmetric supercapacitor by using inorganic electrolyte, Electrochim. Acta, 216 (2016) 332-338. 
[117] E. Lim, C. Jo, H. Kim, M.-H. Kim, Y. Mun, J. Chun, Y. Ye, J. Hwang, K.-S. Ha, K.C. Roh, K. Kang, S. Yoon, J. Lee, Facile Synthesis of $\mathrm{Nb}_{2} \mathrm{O}_{5} @$ Carbon Core-Shell Nanocrystals with Controlled Crystalline Structure for High-Power Anodes in Hybrid Supercapacitors, ACS Nano, 9 (2015) 7497-7505.

[118] Z. Chen, H. Li, X. Lu, L. Wu, J. Jiang, S. Jiang, J. Wang, H. Dou, X. Zhang, Nitrogenated Urchinlike $\mathrm{Nb}_{2} \mathrm{O}_{5}$ Microspheres with Extraordinary Pseudocapacitive Properties for Lithium-Ion Capacitors, ChemElectroChem, 5 (2018) 1516-1524.

[119] C.-H. Lai, D. Ashby, M. Moz, Y. Gogotsi, L. Pilon, B. Dunn, Designing Pseudocapacitance for $\mathrm{Nb}_{2} \mathrm{O}_{5} /$ Carbide-Derived Carbon Electrodes and Hybrid Devices, Langmuir, 33 (2017) 9407-9415.

[120] M.E. Lee, S.Y. Cho, H.J. Yoon, Y.S. Yun, H.-J. Jin, High-performance Li-ion hybrid supercapacitors based on microporous pyropolymer nanoplates and orthorhombic $\mathrm{Nb}_{2} \mathrm{O}_{5}$ nanocomposites, J. Ind. Eng. Chem., 57 (2018) 284-289.

[121] J. Zhai, Y. Wu, X. Zhao, Q. Yang, Facile preparation of flower-like hierarchical $\mathrm{Nb}_{2} \mathrm{O}_{5}$ microspheres self-assembled by nanorod for high-power anodes in advanced hybrid supercapacitor, J. Alloys Compd., 715 (2017) 275-283.

[122] Z.Y. Jia, M.N. Liu, X.L. Zhao, X.S. Wang, Z.H. Pan, Y.G. Zhang, Lithium Ion Hybrid Supercapacitor Based on Three-Dimensional Flower-Like $\mathrm{Nb}_{2} \mathrm{O}_{5}$ and Activated Carbon Electrode Materials, Acta Phys.Chim. Sin., 33 (2017) 2510-2516.

[123] S. Fu, Q. Yu, Z. Liu, P. Hu, Q. Chen, S. Feng, L. Mai, L. Zhou, Yolk-shell $\mathrm{Nb}_{2} \mathrm{O}_{5}$ microspheres as intercalation pseudocapacitive anode materials for high-energy Li-ion capacitors, J. Mater. Chem. A, 7 (2019) 11234-11240.

[124] S. Zhang, J. Wu, J. Wang, W. Qiao, D. Long, L. Ling, Constructing T- $\mathrm{Nb}_{2} \mathrm{O}_{5} @$ Carbon hollow coreshell nanostructures for high-rate hybrid supercapacitor, J. Power Sources, 396 (2018) 88-94.

[125] M. Murugan, R.M. Kumar, A. Alsalme, A. Alghamdi, R. Jayavel, Facile hydrothermal preparation of niobium pentaoxide decorated reduced graphene oxide nanocomposites for supercapacitor applications, Chem. Phys. Lett., 650 (2016) 35-40.

[126] V. Ojha, K. Kato, M.A. Kabbani, G. Babu, P.M. Ajayan, $\mathrm{Nb}_{2} \mathrm{O}_{5} /$ reduced Graphene Oxide Nanocomposite Anode for High Power Hybrid Supercapacitor Applications, ChemistrySelect, 4 (2019) 1098-1102.

[127] X. Shi, S. Zheng, Z.-S. Wu, X. Bao, Recent advances of graphene-based materials for highperformance and new-concept supercapacitors, J. Energy Chem., 27 (2018) 25-42.

[128] J. Lang, X. Zhang, B. Liu, R. Wang, J. Chen, X. Yan, The roles of graphene in advanced Li-ion hybrid supercapacitors, J. Energy Chem., 27 (2018) 43-56.

[129] W. Ni, L. Shi, Layer-structured carbonaceous materials for advanced Li-ion and Na-ion batteries: Beyond graphene, J. Vac. Sci. Technol. A, 37 (2019) 040803.

[130] W. Ni, D. Yang, J. Cheng, X. Li, Q. Guan, B. Wang, Gel-type polymer separator with higher thermal stability and effective overcharge protection of $4.2 \mathrm{~V}$ for secondary lithium-ion batteries, RSC Adv., 6 (2016) 52966-52973.

[131] W. Ni, J. Cheng, X. Li, Q. Guan, G. Qu, Z. Wang, B. Wang, Multiscale sulfur particles confined in honeycomb-like graphene with the assistance of bio-based adhesive for ultrathin and robust free-standing electrode of Li-S batteries with improved performance, RSC Adv., 6 (2016) 9320-9327.

[132] S. Li, T. Wang, W. Zhu, J. Lian, Y. Huang, Y.-Y. Yu, J. Qiu, Y.Zhao, Y.-C. Yong, H. Li, Controllable synthesis of uniform mesoporous $\mathrm{H}-\mathrm{Nb}_{2} \mathrm{O}_{5} / \mathrm{rGO}$ nanocomposites for advanced lithium ion hybrid supercapacitors, J. Mater. Chem. A, 7 (2019) 693-703.

[133] T. Wang, Q. Le, J. Zhang, Y. Zhang, W. Li, Carbon cloth@T- $\mathrm{Nb}_{2} \mathrm{O}_{5} @ \mathrm{MnO}_{2}$ : A rational exploration of manganese oxide for high performance supercapacitor, Electrochim. Acta, 253 (2017) 311-318.

[134] S. Ouendi, C. Arico, F. Blanchard, J.-L. Codron, X. Wallart, P.L. Taberna, P. Roussel, L. Clavier, P. Simon, C. Lethien, Synthesis of T- $\mathrm{Nb}_{2} \mathrm{O}_{5}$ thin-films deposited by Atomic Layer Deposition for miniaturized electrochemical energy storage devices, Energy Storage Mater., 16 (2019) 581-588.

[135] M.A. Aegerter, Sol-gel niobium pentoxide: A promising material for electrochromic coatings, batteries, nanocrystalline solar cells and catalysis, Sol. Energy Mater. Sol. Cells, 68 (2001) 401-422. 
[136] H.-L. Girard, B. Dunn, L. Pilon, Simulations and Interpretation of Three-Electrode Cyclic Voltammograms of Pseudocapacitive Electrodes, Electrochim. Acta, 211 (2016) 420-429.

[137] R. Thangavel, K. Kaliyappan, D.-U. Kim, X. Sun, Y.-S. Lee, All-Organic Sodium Hybrid Capacitor: A New, High-Energy, High-Power Energy Storage System Bridging Batteries and Capacitors, Chem. Mater., 29 (2017) 7122-7130.

[138] H. Kim, E. Lim, C. Jo, G. Yoon, J. Hwang, S. Jeong, J. Lee, K. Kang, Ordered-mesoporous $\mathrm{Nb}_{2} \mathrm{O}_{5}$ /carbon composite as a sodium insertion material, Nano Energy, 16 (2015) 62-70.

[139] Z. Tong, S. Liu, Y. Zhou, J. Zhao, Y. Wu, Y. Wang, Y. Li, Rapid redox kinetics in uniform sandwichstructured mesoporous $\mathrm{Nb}_{2} \mathrm{O}_{5} /$ graphene/mesoporous $\mathrm{Nb}_{2} \mathrm{O}_{5}$ nanosheets for high-performance sodium-ion supercapacitors, Energy Storage Mater., 13 (2018) 223-232.

[140] Y. Li, H. Wang, L. Wang, Z. Mao, R. Wang, B. He, Y. Gong, X. Hu, Mesopore-Induced Ultrafast $\mathrm{Na}^{+}$-Storage in $\mathrm{T}-\mathrm{Nb}_{2} \mathrm{O}_{5} /$ Carbon Nanofiber Films toward Flexible High-Power Na-Ion Capacitors, Small, 15 (2019) 1804539. 